\title{
„Aber die wichtigste Heeresmacht mit acht Legionen stand am Rhein zum Schutz zugleich gegen Germanen und Gallier“6 - Tacitus (ann. 4,5,1) zum Jahr 23
}

\author{
Rainer Wiegels
}

\section{Zusammenfassung}

Im Frühjahr 23 n. Chr. sah sich Kaiser Tiberius veranlasst, dem Senat Bericht zu erstatten über die Lage im Heer und die Schwierigkeiten der Gewinnung von Rekruten. Tacitus nimmt dies seinerseits zum Anlass, mit Bezug auf die seinerzeitige Situation über die Verteilung der wichtigsten Truppenverbände an den verschiedenen Reichsgrenzen zu informieren. Der Zeitpunkt des kaiserlichen Rapports an den Senat war offenbar nicht zufällig gewählt, das Jahr 23 wird später von Tacitus als Wendepunkt im persönlichen Verhalten und in der Politik des Tiberius angesehen. Bei der Übersicht über die Truppen und deren Stärke fällt hinsichtlich der Rheinfront der betonte Hinweis auf, dass diese nicht nur zum Schutz gegen Germanien, sondern auch gegen Gallien dienen sollten. In diesem Beitrag soll zunächst das historische Umfeld erörtert werden, in welches maßgeblich Anlass und Zeitpunkt der Mitteilung des Kaisers an den Senats und die Übersicht über die Heeresstärke eingeordnet werden können (I.). In einem zweiten Punkt wird auf einige grundlegende Aspekte der Grenzpolitik des Tiberius nach Abberufung des Germanicus von der Rheinfront eingegangen werden (II.). Schließlich soll auf die besondere Situation der Truppen am Rhein und ihren Bezug zum inneren, vornehmlich östlichen Gallien hingewiesen werden (III.).

\section{Anlass und historisches Umfeld}

Im Frühjahr $23^{1}$ sah sich Kaiser Tiberius veranlasst, dem Senat Bericht zu erstatten über die aktuelle Situation bei den Truppen und die Schwierigkeit, Freiwillige zum Dienst in den Heeren zu bewegen. ${ }^{2}$ Auch die große Anzahl von Veteranen würde neue Aushebungen erforderlich machen. Zudem gab er einen kursorischen Überblick (cursim) über die Anzahl der Legionen und die Provinzen, die sie zu schützen hätten (Tac. ann. 4,4,3). An vorderster Stelle wird mit dem hier in der Überschrift wiedergegebenen Zitat Bezug genommen auf die Truppen am Rhein. ${ }^{3}$ Zur Sprache kam nach Tacitus auch der alte,

\footnotetext{
${ }^{1}$ Sofern nicht ausdrücklich vermerkt, beziehen sich alle Datierungen im Folgenden auf die Zeit „n. Chr.“

${ }^{2}$ Entsprechend der Zuordnung der Truppenverbände zu verschiedenen Bereichen ist die Rede von „Heeren“, also exercitus im Plural!

${ }^{3}$ In der Formulierung des Tacitus: Sed praecipuum robur Rhenum iuxta, commune in Germanos Gallosque subsidium, octo legiones erant. Diese Mitteilung des Historikers wird zwar häufiger zitiert, selten aber interpretiert. Jedoch dient sie als Ausgangspunkt in der Zusammenfassung des Forschungsstandes zum römischen Militär in Gallien bei REDDÉ 1987, 343, der ihr zudem den Hinweis Galbas anlässlich der Adoption Pisos auf die Revolte des Statthalters der Gallia Lugdunensis im Jahr 68 an die Seite stellt, die Vindex cum inermi provincia angezettelt habe (Tac. hist. 1,16,2). Desgleichen verweist er auf Flavius Josephus (b. Iud. 2, 371-373). In dessen Übersicht über die Provinzen des Reiches vermerkt dieser zu Gallien: „Obgleich sie (d.h. die Gallier) die Quellen ihres Reichtums sozusagen im eigenen Hause haben und mit ihren Gütern fast die ganze Welt überschwemmen, dulden sie es doch, von den Römern gründlich ausgesogen zu werden und gestehen zu, dass diese ihren Reichtum verwalten. Sie lassen sich dies nicht aus Feigheit oder Ehrlosigkeit gefallen, haben sie doch 80 Jahre lang den Kampf für ihre Freiheit durchgestanden; aber sie wurden nicht durch die Kriegsmacht, sondern auch durch das Kriegsglück der
} 
schon oft nur zum Schein vorgebrachte Plan einer Reise des Princeps in die Provinzen, der jedoch weder zu diesem Zeitpunkt noch in den Folgejahren realisiert wurde. ${ }^{4}$ Der sarkastische Unterton des Historikers ist offenkundig; die Frage nach den gegebenenfalls in Aussicht genommenen konkreten Zielen blieb oder bleibt wohl mit Absicht unbeantwortet (Tac. ann. 4,4,2 f.).

Bekanntlich hat Tiberius Rom und Italien seit Übernahme des Principats 14 bis zu seinem Tod im Jahr 37 nicht mehr verlassen und die Regelungen der Angelegenheiten in den Provinzen seinen Beauftragten, in Krisengebieten mit starker Truppenmacht insbesondere seinen nahen Angehörigen, überantwortet. ${ }^{5}$ Neben persönlicher Vorliebe und der Überzeugung des Vorrangs von Rom und Italien gegenüber den Provinzen dürften auch politische Gründe für Tiberius eine Rolle gespielt haben, insofern die Verantwortung für das gesamte Imperium und die maiestas des Princeps, aber auch die innere Sicherung der noch jungen Herrschaft seine Anwesenheit im Zentrum des Reiches als wünschenswert, wenn nicht als notwendig erscheinen ließen. Die folgenden Kaiser haben sich diesbezüglich aus grundsätzlicher Einstellung oder auch situationsbedingt unterschiedlich verhalten. Tacitus stand nicht zuletzt unter dem Eindruck des jahrelang persönlich an den Fronten agierenden Traian. Aber auch Augustus hatte seit 8 v. Chr. Italien nicht mehr verlassen. Bemerkenswert ist allerdings auch, dass nachweislich zumindest in zwei Fällen Statthalter von militärisch bedeutenden Provinzen in der Regierungszeit des Tiberius ihr Amt über lange Jahre in absentia von Rom aus

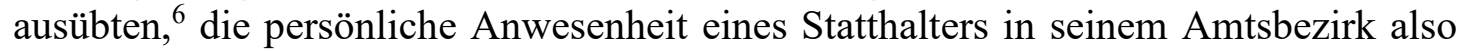

Römer erschüttert, das jenen mehr Siege einbrachte als die Waffen. So dienen sie nun den Römern unter einer Besatzung von 1200 Soldaten, und dabei haben sie selbst fast noch eine größere Anzahl von Städten" (Ü: O. Michel u. O. Bauernfeind). - Als Besatzung wird hier auf die in Lugdunum/Lyon stationierte cohors XIII urbana verwiesen.

${ }^{4}$ Bereits von Januar 21 bis Mitte 22 hatte sich Tiberius in Campanien aufgehalten, wobei er schon damals beabsichtigt haben soll, sich für lange Zeit oder auch auf Dauer dorthin zurückzuziehen; die Rückkehr nach Rom sei dann wegen einer schweren Erkrankung der Iulia Augusta erfolgt (Tac. ann. 3,31,2; 3,64,1). Die Umstände veranlassen Tacitus zu verschiedenen Vermutungen (und auch Unterstellungen), was die Absichten des Princeps betraf. Nach Campanien begab sich der Kaiser dann wieder 26 und wählte ab dem folgenden Jahr Capri zu seinem dauerhaften Wohnsitz (Tac. ann. 4,57; 4,67; Suet. Tib. 38 f.; vgl. Dio 58,1(1)). Nach Sueton (Tib. 38) soll er sogar Gelübde für seine glückliche Reise und Rückkehr zugelassen haben, die aber nie erfolgte, was ihm allenthalben den witzigen Namen „Kallipides“ einbrachte gemäß einem griechischen Scherzwort für eine Person, die rennt und rennt, aber kein Stück voran kommt. ${ }^{5}$ Obwohl selber militärisch bestens erfahren und im rüstigen Alter von 56 Jahren, entsandte Tiberius in der Nachfolge des Augustus als Princeps seine Söhne Drusus und Germanicus zur Niederschlagung von Aufstandsbewegungen bei den pannonischen und rheinischen Legionen. Dies führte in Senat und Bürgerschaft von Rom zu heftiger Kritik, wie Tacitus (ann. 1,46 f.) vermerkt mit der dem Princeps zugeschriebenen eingehenden Rechtfertigung, wonach er die Oberaufsicht von Rom aus in Händen halte und es problematisch sei, wenn er zu einem der beiden gleichermaßen für Rom gefährlichen Aufstandsbewegungen reise; vgl. auch Tac. ann. 3,47,2 zum Jahr 21. Anders Dio 57,3,2: Vorspiegelung von Krankheit. ${ }^{6}$ Vgl. Suet. Tib. 63,2. - L. Aelius Lamia versah das Amt des Statthalters von Syrien von 21-31 in absentia (PIR ${ }^{2}$ A 200), L. Arruntius ebenfalls in absentia dasjenige von Hispania citerior von 25 bis mindestens 33 oder 35, vgl. dazu Tac. hist. 2,65,2: ... Arruntium Ti. Caesar ob metum ... retinebat; Tac. ann. 6,27,2 f. (PIR ${ }^{2}$ A 1130). Im Übrigen beließ Tiberius manche Legaten und Prokonsuln länger in ihrem Amt als üblich: C. Poppaeus Sabinus war von 11 (oder 12) bis 35 Legat des Kaisers in Moesien, und zwar zunächst des Augustus, dann des Tiberius, der ihm 15 zusätzlich Achaia und Macedonien unterstellte (PIR ${ }^{2}$ P 847). C. Silius A. Caecina Largus kommandierte von 14-21 das obergermanische Heer, also auch noch nach Abberufung des Germanicus Ende 16 ( PIR $^{2}$ S 718) und Cn. Cornelius Lentulus Gaetulicus dasselbe von 29/30-39 (PIR ${ }^{2}$ C 1390). Die Dauer der Kommanden über das niedergermanische Heer unter Tiberius ist unsicher. Pontius Pilatus amtierte als praefectus Iudaeae von 26-36/37 (PIR ${ }^{2}$ P 815).

http://www.fera-journal.eu 
nicht grundsätzlich als unabdingbar angesehen wurde. ${ }^{7}$ Tacitus nimmt die Ausführungen des Tiberius gegenüber dem Senat zum Anlass, seinerseits darüber zu berichten, welche Heeresmacht Roms damals an welchen Fronten unter Waffen stand, welche Könige seine Verbündete waren und darauf hinzuweisen, wieviel begrenzter damals Roms Herrschaftsbereich war. ${ }^{8}$ Diese letzte Feststellung trifft Tacitus auf vor dem Hintergrund der in den folgenden Jahrzehnten bis zur Herrschaft Traians erfolgten Ausweitung des Imperiums.

Nicht von ungefähr erfolgte die von Tiberius dem Senat gegenüber dargelegte Übersicht über die Heeresstärke in den Provinzen zu Beginn des Jahres 23. Von Tacitus, der Tiberius eher ablehnend bis feindlich gesonnen war, wird dieses Jahr nach dem Tod seines Sohnes Drusus und wohl auch infolge desselben als Wendepunkt im Verhalten des Princeps angesehen, insofern dieser nunmehr seiner bislang scheinheilig unterdrückten Grausamkeit nicht ohne wachsenden Einfluss des Prätorianerpräfekten L. Aelius Seianus freien Lauf ließ (Tac. ann. 4,1,1; 4,7,1). ${ }^{9}$ Eine zunehmend wichtige Rolle spielte der Umstand, dass nach dem Tod des Germanicus im Jahr 19 die Sukzessionsfrage in der Funktion des Princeps offen war. Immer deutlicher erkennbar wird das Bemühen des Tiberius, nunmehr seinen leiblichen Sohn Drusus als Nachfolger aufzubauen (vgl. Tac. 2,43,5 bereits zum Jahr 17). ${ }^{10}$ Dagegen scheint Augustus die Suk-

\footnotetext{
${ }^{7}$ Dies und die häufig über eine vergleichsweise lange Dauer verliehenen Amtsgewalten haben schon in der Antike zu manchen Spekulationen über die Gründe geführt, welche Tiberius zu diesem Vorgehen veranlasst haben mögen. Zu den verschiedenen Vermutungen, die diesbezüglich kursierten, s. Tac. ann. 1,80. Mäßige Bereitschaft unter den führenden Senatoren, Provinzkommanden zu übernehmen, beklagte Tiberius im Jahr 33, s. Tac. ann. 6,27,2 f. mit verschiedenen Erwägungen des Historikers über die Ursachen; vgl. auch Dio 58,23,5, wonach der Mangel an geeigneten Kandidaten angesichts der Dezimierungen innerhalb der Aristokratie durch Verurteilungen das entscheidende Argument für die Prolongierungen gewesen sei.

${ }^{8}$ Tac. ann. 4,4,3: „... mihi quoque exsequendum reor, quae tunc Romana copia in armis, qui socii reges, quanto sit angustius imperitatum." - Berichte über die Verteilung von Besatzungen im Reichsgebiet aus früherer Zeit finden sich etwa bei Orosius $(6,19,14$ : offenbar pauschal aus seiner Quelle zusammengezogen) zum Jahr 30 v. Chr. (Brundisium) und Cassius Dio $(55,23,2-7)$ zum Jahr 5 n. Chr. Jedoch sind die Angaben bei Dio zweifellos unkorrekt, s. Ritterling 1924/25, 1215 ff. mit Hinweis auf die schwierige und teilweise problematische Quellenlage zur Verteilung der einzelnen Legionen auf die verschiedenen Provinzen in der Frühphase des Principats. Eine deutliche Parallele zum Vorgehen des Tiberius im Jahr 23 liefert die Rechenschaftsablegung des Augustus im Jahr 14 in einer Denkschrift (libellum) über die Machtmittel des Staates (opes publicae), welche Tiberius nach dessen Tod im Senat verlesen ließ. Mit eigener Hand hatte Augustus verzeichnet, wie viele Bürger und Bundesgenossen unter Waffen standen, wie viele Flotten, Königreiche und Provinzen es gab, dazu die Tribute oder indirekten Steuern und auch notwendige Ausgaben und Schenkungen (Tac. ann. 1,11,4: ...opes publicae continebantur, quantum civium sociorumque in armis, quot classes regna provinciae, tributa aut vectigalia, et necessitates ac largitiones).

${ }^{9}$ Entsprechend der unterschiedlichen Wertung des Principats des Tiberius in den antiken Quellen ist auch die moderne Forschung gespalten, was Person und Politik des Nachfolgers des Augustus betrifft. Generell festzustellen ist jedoch aktuell eine Tendenz, Maßnahmen und Herrschaft des Tiberius positiver zu beurteilen als es bei einem einseitigen Bezug auf Tacitus bisweilen geschieht, indem Tiberius gleichsam als ein finsterer Tyrann erscheint. S. dagegen etwa KORNEMANN 1960, der geradezu euphorisch den Princeps und seine Herrschaft lobt und in ihm einen Märtyrer sieht, der ungerechterweise verunglimpft worden sei; vgl. dazu und zur „Tragödie des Herrschers“ auch MEYER 1962, 101-103, mit Bezug vor allem auf dessen Persönlichkeit, sowie die Biographie von YAVETZ 1999 zum „traurigen Kaiser“ - nach Plin. n. h. 28,23: tristissimus, ut constat, hominum. Reservierter zur Gesamtbeurteilung u.a. schon GELZER 1919; eingehend insbesondere unter Bezug auf die Darstellung des Tiberius bei Tacitus auch SYME 1958, 420-434 u. ö., der in der Beurteilung des Tiberius durch Tacitus auch einen Reflex des DomitianErlebnisses des Historikers sieht; s. ferner ALFÖLDY 1965.

${ }^{10}$ Kritische Bemerkungen seitens des Princeps zu Charakter und Lebenswandel seines Sohnes überliefert Dio 57,13,1 f.; 57,14,9 f.; vgl. auch Suet. Tib. 52,1 f. Dazu LEVICK 1999, bes. 158 mit Anm. 54 und
} 
zessionsfolge den Söhnen des Germanicus zugedacht zu haben, da er in seinem Testament diese als Caesaren bezeichnet hatte (Dio 57,18,11). ${ }^{11}$ Anfang 21 traten Tiberius sein viertes und Drusus sein zweites Konsulat an. ${ }^{12}$ Ein Jahr später erhielt Drusus die tribunicia potestas, ein Vorrecht, welches Germanicus nie zugestanden worden war. An der vorgesehenen Rolle für Drusus konnte kein Zweifel mehr bestehen (bes. Tac. ann. 3,56; 59,2-4). ${ }^{13} \mathrm{Zu}$ Beginn des Jahres 23 hatte Drusus Iulius Caesar, einer der Söhne des Germanicus, die Männertoga angelegt, und der Senat hatte für diesen dieselben Vor- und Ehrenrechte beschlossen wie für dessen älteren Bruder Nero Iulius Caesar drei Jahre zuvor, darunter Befreiung vom Vigintivirat und Bewerbung um die Quästur fünf Jahre vor der gesetzlichen Frist (Tac. ann. 3,29,1-4). Der plötzliche Tod des Sohnes des Tiberius im September $23^{14}$ führte jedoch zu wachsenden Spannungen innerhalb der domus Augusta, welche sich insbesondere an der nunmehr erneut offenen Nachfolgefrage entzündeten, zumal wenige Jahre zuvor diesem Drusus Zwillingsöhne geboren worden waren. ${ }^{15}$ Die Übersicht des Tiberius über die Heere und Provinzen zu Beginn des Jahres war jedenfalls auch dazu geeignet, auf die Notwendigkeit einer erfahrenen Persönlichkeit in der Funktion des Princeps für die Gewährleistung der Sicherheit des Imperiums hinzuweisen, wofür Drusus (d. J.) zu diesem Zeitpunkt noch bereit stand. ${ }^{16}$ Grundsätzlich waren bekanntlich die Stellung des Princeps und damit insbesondere die Sukzessionsfrage eine heikle, weil nicht konstitutionell abgesicherte Angelegenheit. Dabei spielte das dynastische Prinzip zwar eine wichtige, aber nicht die ausschließliche Rolle. Mit Drusus (d. J.) wurde von Tiberius eine Person favorisiert, welche nur mittelbar mit der iulischen Linie des Augustus verbunden war. Zudem ist nicht zu übersehen, dass der Princeps in der Öffentlichkeit seine eigene familiäre Abstammung gleichsam als neue Dynastie herausstellte. Umso wichtiger war es, zur Sicherung des Anspruchs auf Nachfolge auf weitere Elemente der Legitimation zu setzen, im vorliegenden Fall das Heer und die militärische Kompetenz eines verantwortlichen Befehlshabers.

weiteren Belegen für Zügellosigkeit und Grausamkeit seines Charakters. Dieses wurde aber auch Tiberius selber zur Last gelegt, vgl. etwa den Epilog des Tacitus auf Tiberius in ann. 6,51,3 oder Suet. Tib. 42-45; 57; 61 f. mit Cal. 6,2.

${ }^{11}$ Zum Zeitpunkt des Todes des Germanicus waren dessen Söhne Nero Iulius Caesar 15, Drusus Iulius Caesar 12 und C. Caesar Germanicus (Caligula) 8 Jahre alt. - Zu den Söhnen vgl. PIR ${ }^{2}$ I 232; I 220 und I 217. - Zur Sukzessionsfrage SEAGER 2005, 100-103. Lesenswert sind auch die entsprechenden Ausführungen in der ,klassischen“ und viel beachteten älteren Biographie zu Tiberius von MARSH 1931, 160 199.

${ }^{12}$ Drusus war 15 oder 14 v. Chr. als Sohn des Tiberius und der Vipsania Agrippina geboren worden. Nach Adoption des Tiberius durch Augustus 4 n. Chr. erhielt er den Namen Drusus Iulius Caesar und heiratete wenig später Livia Iulia, die Schwester des Germanicus und Witwe des Gaius Caesar. Cos I war er im Jahr 15. Die gemeinsame Bekleidung des Konsulats durch Vater und Sohn im Jahr 21 wurde in der Öffentlichkeit stark beachtet. - Übersicht zur Vita s. etwa PIR 2 I 219.

${ }^{13}$ Nach Tac. 2,43,6 und 4,4,1 bestand zwischen Drusus und den Söhnen des Germanicus ein gutes Einvernehmen. Zumindest seien sie einander nicht feindlich gesonnen gewesen.

${ }^{14}$ Die Quellen gehen von Giftmord aus, vgl. ausführlich Tac. ann. 4,7-11 (auch zu diesbezüglichen Gerüchten); Dio 57,22,1-4 mit (4a)-(4b) (= Zonaras 11,2); Suet. Tib. 62,1; Euseb. Chron. p. 172 (Helm). Nach Ios. ant. Iud. 18,206 starb Drusus eines natürlichen Todes. Der Giftmord und die später Seianus und Livia Iulia (Livilla) unterstellte Teilnahme an diesem sind zu bezweifeln, vgl. auch LEVICK 1999, bes. 160 f.; 178; 274 Anm. 71 und SEAGER 2005, 154-157, jeweils mit den Verweisen und weiterer Literatur.

${ }^{15}$ Ti. Iulius Caesar Nero (= Ti. Gemellus bei Ios. ant. Iud. 18,206) und Germanicus Iulius Caesar; vgl. PIR $^{2}$ I 226 und I 224. Letzterer verstarb aber in demselben Jahr wie sein Vater Drusus (d. J.). - Der Bezug von CIL V $4311=$ ILS $170=$ IIt. X,5, 736 (Brixia/Brescia) auf die Zwillinge wird jetzt aber verworfen, vgl. AE 2003, 715. Nach Dio 57,14,6 war ein älterer Sohn des Drusus bereits 15 verstorben.

${ }^{16}$ Zwischen 14 und 20 war Drusus mehrfach als Befehlshaber nach Illyricum gesandt worden, s. auch im Folgenden. 


\section{Nach Abberufung des Germanicus: Aspekte der Grenzpolitik und der Auf- stand der Treverer}

Der Principat des Tiberius nach Abberufung des Germanicus und dem Ende der Offensivkriege am Rhein gilt allgemein als eine weitgehend friedliche Phase des Imperiums, ${ }^{17}$ in welcher insbesondere Maßnahmen der Grenz- und Herrschaftssicherung Roms im Vordergrund standen gemäß dem Vermächtnis des Augustus, das Reich innerhalb der bestehenden Grenzen zu belassen. ${ }^{18}$ Allerdings vermelden die Annalen doch auch verschiedene Aufstandsbewegungen, welche militärisches Eingreifen seitens Rom erforderlich machten, und dazu weitere Ordnungsmaßnahmen in den Grenzgebieten. ${ }^{19}$ Die Mission des Germanicus in den Osten beruhte auf dem Auftrag, auf diplomatischem Weg einen Ausgleich zwischen Rom und den Parthern in der strittigen Frage der Kontrolle über den jeweils in Armenien regierenden König zu erreichen und möglichst dauerhaft zu befestigen, was schließlich auch mit der Einsetzung von Artaxias III gelang, der 17 Jahre lang bis 34 herrschte. Die folgenden Turbulenzen mit Parthien konnten schließlich mit militärischem Druck und Diplomatie im Sinne Roms beigelegt werden, was aber schon über den Principat des Tiberius hinaus weist. ${ }^{20}$ Bereits 17 waren mit der Annexion von Cappadocien und Commagene im Osten ohne größeren militärischen Einsatz wichtige Gebiete für Rom gewonnen worden. ${ }^{21}$ Größere Unruhen bei den Stämmen im Donauraum und insbesondere in Thrakien führten dagegen ab 17 $\mathrm{zu}$ einem umfassenden Kommando mit prokonsularischem Imperium über die Gebiete von Illyricum, Pannonia, Raetia und Noricum für Drusus, das er bis Anfang 20 innehatte. $^{22}$ Für seine Erfolge wurde er in demselben Jahr mit der ovatio ex Illyrico geehrt (Fasti Ost. [28. Mai 20]; Tac. ann. 3,11,1; 18,3; 19,3; vgl. 3,56,4). Ein weiterer Unruheherd war Afrika auf Grund der Rebellion des Tacfarinas, eines ehemaligen Führers einer Auxiliareinheit in römischen Diensten und militärisch gut geschult. Die Auseinandersetzungen mit Rom zogen sich in verschiedenen Etappen von 17 bis 24 hin. ${ }^{23}$ Bedrohlich war die Revolte vor allem wegen der Abhängigkeit Roms von der Kornversorgung aus Afrika, ${ }^{24}$ aber ernsthaft gefährdet war das Imperium durch die sich mehr und mehr zu einem Partisanenkrieg entwickelnde Auseinandersetzung letztlich nicht. ${ }^{25}$

\footnotetext{
${ }^{17}$ Elogen auf die Friedenszeit u.a. bei Vell. 2,131 im panegyrischen Schlussgebet oder Philo leg. 141: Dank der Provinzen.

${ }^{18}$ Tac. ann. 1,11,4: consilium coercendi intra terminos imperii als Vermächtnis des Augustus, welches die Denkschrift (libellum) des Verstorbenen enthielt, die Tiberius im Senat nach dessen Tod verlesen ließ, s. oben Anm. 7. Gelegentlich wird dieser Rat als ein von Tiberius eingefügter Zusatz angesehen, jedoch ist dies weder beweisbar noch zwingend anzunehmen. Ferner Dio 56,33,5; vgl. auch Tac. ann. 4,32,2: princeps proferendi incuriosus; Tac. Agr. 13,2.

19 Überblicke u.a. bei MARSH 1931, 134-159; LEVICK 1999, 125-147 oder SEAGER 2005, 138-147. Eine grundsätzliche Analyse der Provinzpolitik des Tiberius liefert insbesondere ALFÖLDY 1965; ferner ORTH 1970.

${ }^{20}$ Mission des Germanicus mit proconsularischem Imperium in den Osten: Tac. ann. 2,43,1 f.; 56-58; Suet. Cal. 1,2. - Spätjahre des Tiberius ab 35: Tac. ann. 6,31-37; 42-44; Ios. ant. Iud. 18,96-100; Dio $58,26,1$.

${ }^{21}$ Vgl. dazu LEVICK 1999, 141 mit ausführlichem Quellenbezug in Anm. 64.

22 Tac. ann. 2,44-46; 53,1; $62-68$ (u.a. zu Marbod); 3,38 f.; Vell. 2,129,3. - Für die Folgezeit vgl. Tac. ann. 4,5,3; 4,46-51 zum Jahr 26.

${ }^{23}$ Im Jahr 20 wurde die legio IX Hispana aus Pannonien zur Verstärkung der in Numidien stationierten legio III Augusta nach Afrika gesandt, aber 24 wieder zurückbeordert. - Vgl. zur Auseinandersetzung Roms mit Tacfarinas zuletzt LE BOHEC 2019.

${ }^{24} \mathrm{Vgl}$. u.a. Ios. b. Iud. 2,383, wonach zwei Drittel des Korns für Rom aus Afrika importiert wurden. Von drückender Teuerung mit der Folge der Festsetzung eines Höchstpreises für Getreide berichtet Tacitus (ann. 2,87) zum Jahr 19. Unruhen wiederholten sich u.a. im Jahr 32, vgl. Tac. ann. 6,13.

25 Tac. ann. 2,52; 3,20 f.; $38 \mathrm{f}$.
} 
Auch der Friesenaufstand des Jahres 28 blieb ein kurzfristiges, regionales Ereignis, weist aber einige typische strukturelle Elemente auf. ${ }^{26}$ Darauf wird noch zurückzukommen sein. Ebenfalls von begrenzter Bedeutung war das Eingreifen der Legionen Syriens in Iudaea bei internen Auseinandersetzungen um die dortige Herrschaft gegen Ende der Regierung des Tiberius, ein Vorgehen, das allerdings wegen des Herrschaftswechsels in Rom abgebrochen wurde. ${ }^{27}$

Als gefährlicher eingestuft wurde nach Tacitus von der Bevölkerung Roms der Aufstand gallischer Stämme im Jahr 21 wegen drückender Schuldenlast. ${ }^{28}$ Hierfür mag die Nähe zu Italien und Rom eine Rolle gespielt haben. Tacitus berichtet relativ ausführlich, wobei es ihm aber offenbar besonders um die Darlegung innenpolitischer Verflechtungen und Konsequenzen geht (Tac. ann. 3,40-47). ${ }^{29}$ Denn die Ereignisgeschichte selber zeigt, dass kein ernsthafter Anlass zur Sorge um die Herrschaft Roms und die Sicherheit seiner Zentrallande bestand. ${ }^{30}$

Bei dem Aufstand taten sich bei den Treverern Iulius Florus und bei den Haeduern Iulius Sacrovir als Rebellenführer besonders hervor. ${ }^{31}$ Beide gehörten zu den führenden Persönlichkeiten ihrer Stämme, beide besaßen aber auch aufgrund von Verdiensten ihrer Vorfahren das römische Bürgerrecht. ${ }^{32}$ Sie planten die Aufwiegelung weiterer Stämme wie der Belger und der den Haeduern benachbarten Stämme (Tac. ann. 3,40,3). Letztere werden an dieser Stelle nicht eigens aufgeführt, später werden Turonen und Andecaver genannt (Tac. ann. 3,41,1 f.; 46,2), die im Bereich der Loire siedelten, ferner die Sequaner im südöstlichen Gallien zwischen Saône und Jura, deren Gaue an der äußersten Grenze Galliens zum obergermanischen Heeresbezirk liegen (Tac. ann. 3,45,1; 46,2). Unklar bleibt dagegen das nähere Verhältnis zu den Lingonen. ${ }^{33}$ Eine wenig homogene Gruppe bilden die Belgae im Norden und Nordosten Gal-

\footnotetext{
${ }^{26}$ Tac. ann. 4,72-74,1. Die Friesen sorgten allerdings auch noch in der Folgezeit für Unruhen, die erst Cn. Domitius Corbulo im Jahr 47 durch Ansiedlung beilegte, vgl. Tac. ann. 11,19,1; s. aber wiederum Tac. ann. 13,54 zum Jahr 58.

${ }^{27}$ Ios. ant. Iud. 18,109-126.

${ }^{28}$ Tac. ann. 3,40,1: Galliarum civitates ob magnitudinem aeris alieni rebellionem coeptavere. $-\mathrm{Zu}$ den Gerüchten in Rom s. Tac. ann. 3,44 und dazu weiter unten mit Anm. 61.

${ }^{29}$ Die ältere Forschung übernahm häufig mehr oder weniger unkritisch die Perspektiven des Tacitus, vgl. JULLIAN 1920, 153-160; WIGHTMAN 1970, 38 f.; DYSON 1975, 152-161, bes. 156 ff.; LEWUILLON 1975, 511-520, bes. 513 f.; HEINEN 1988, 56-60. - Differenzierter u.a. DRINKWATER 1978, 27 ff.; HERZ 1992; URBAN 1999, 39-45, s. auch weiter unten. - Die schwer zu klärende Frage nach den Quellen des Tacitus muss an dieser Stelle unbeantwortet bleiben, s. dazu etwa MARSH 1931, 233-266.

${ }^{30}$ Anzumerken ist, dass weder Sueton noch Cassius Dio über den Aufstand berichten, allerdings liegen für die fragliche Zeit lediglich Excerpte aus Dio vor. Unspezifisch ist die Mitteilung bei Suet. Tib. 37,4, wonach Tiberius Erhebungen von Feinden durch Legaten habe niederschlagen lassen.

${ }^{31} \mathrm{Zu}$ Iulius Florus s. etwa BURNAND 2005/10, I 137-139 Nr. 1 u. ö.; zu Iulius Sacrovir etwa BuRNAND 2005/10, I 137-139 Nr. 2 u. ö.

32 Tacitus (ann. 3,40,1 f.) verbindet die Erhebung unmittelbar mit den Personen Florus und Sacrovir als den tatkräftigsten Rädelsführern (exstimulatores acerrimi) unter Beiziehung der verwegensten Leute oder solchen, welche sich aus Not oder aus Furcht wegen ihrer Schandtaten besonders zu Vergehen veranlasst sahen (... ferocissimo quoque adsumpto aut quibus ob egestatem ac metum ex flagitiis maxima peccandi necessitudo). Das spricht gegen eine breite Beteiligung der Eliten. Beide Anführer sind aber keine Freiheitshelden, wie HATT 1970, 123 f. in Bezug auf die Erhebung meint: „...la dernière revolte proprement nationaliste de la Gaule“. Zuvor ging schon GRENIER 1936, bes. 386 von einer Verbindung des Widerstandes gegen ökonomische Ausbeutung durch die Römer mit einem alten Bewusstsein und Bestreben nach ,nationaler Unabhängigkeit und Freiheit' bei den primores Galliarum aus; ähnlich THEVENOT 1960/61 zu Sacrovir; CHRISTOPHERSON 1968, 355. Dagegen s. LEWUILLON 1975, 513 ff., bes. 517-521; BESSONE 1978 und besonders URBAN 1999, $43 \mathrm{f}$.

${ }^{33}$ Sie könnten in die zusammenfassende Bemerkung von den „benachbarten Stämmen“ einbezogen gewesen sein. - Zur Agitation des Lingonenführers Iulius Sabinus beim gallischen Aufstand 69/70 s. Tac.
} 
liens, die wie auch die Treveri dem germanischen Kreis nahe standen. Warum abgesehen von persönlichen Ambitionen der beiden Anführer der Rebellion die (H)Aedui und Treveri das Zentrum der Erhebung bildeten, ist nicht einfach zu erklären und erfordert einige übergreifende Überlegungen und Erklärungsversuche. Wohl nicht zufällig befanden sich die Territorien der beiden Civitates im östlichen Gallien in nicht allzu großer Entfernung voneinander, und römischer Straßenbau ermöglichte eine bequeme und schnelle Kommunikation. ${ }^{34}$

Die Haeduer galten lange als mächtigster Stamm Galliens und waren zeitweise eng mit Rom verbündet. ${ }^{35}$. Ihre Hauptstadt war seit augusteischer Zeit Augustodunum/Autun, das sich rasch $\mathrm{zu}$ einem politischen, wirtschaftlichen und geistigen Zentrum Galliens entwickelte und kaum hinter Lugdunum/Lyon rangierte. In der Ansprache des römischen Kommandanten C. Silius an seine Soldaten vor dem Kampf mit den Haeduern werden diese als unkriegerisch (imbelles), weil dem Geld und Luxus verpflichtet, charakterisiert: „Diese an Geld reichen und in Luxus schwelgenden, aber umso unkriegerischen Haeduer - besiegt sie gänzlich und schont die Fliehenden" (Tac. ann. 3,46,2). ${ }^{36}$ Nach der Verleihung des ius honorum an die Gallier durch Kaiser Claudius im Jahr 48 gelangten aus diesem Stamm die ersten Notablen Galliens in den römischen Senat (Tac. ann. 11,25,1: quia soli Gallorum fraternitatis nomen populo Romano usurpant [alleine unter den Galliern im Besitz des Titels der „Brüderschaft mit dem römischen Volk"]). Kriegerische Tradition scheint im Verlauf der Kaiserzeit nur noch eine geringe Rolle gespielt zu haben. Eine electa iuventus der Haeduer (wohl Miliz) war zwar auch 69 im Einsatz (Tac. hist. 2,61), jedoch erfolgte wohl nicht von ungefähr aufgrund des Rechtsstatus dieser civitas als civitas foederata keine Conscription einer geschlossenen ,nationalen' Einheit aus diesem Stamm. Zu diesen civitates foederatae gehörten nach Plin. n. h. 4,106 f., basierend wohl auf der Weltkarte des Agrippa und dem gallischen Zensus des Jahres 12 v.Chr., neben den Haeduern auch Remer $^{37}$, Carnuten ${ }^{38}$ und Lingonen ${ }^{39}$, die ebenfalls in vorflavischer Zeit keine ,nationalen' Kontingente als geschlossene Auxilien stellten. ${ }^{40}$ Sie waren offenbar in

hist. 4,55,3 f., der eine besonders enge Verbindung zwischen ihm und den Treverern Iulius Classicus und Iulius Tutor hervorhebt. Nach Dio 65,3(1) hatte Sabinus aus eigenen Mitteln eine persönliche und unabhängige Streitmacht gesammelt, dagegen stellte nach Frontin. strat. 4,3,14 die opulentissima civitas Lingonum, welche von den anrückenden Römern geschont worden war, nach Unterwerfung diesen 70.000 Mann in Rüstung zur Verfügung, was aber zweifellos weit übertrieben ist oder auf einem Überlieferungsfehler beruht. - Zur Person s. BuRNAND 2005/10, I 137-139 Nr. 6 u. ö.

${ }^{34}$ Offen ist die Parteiname von Leukern und Mediomatrikern, deren Stammesgebiete zwischen denjenigen der Haeduer und Treverer lagen.

${ }^{35}$ Vgl. u.a. WOLTERS 1990, bes. 30-46; 72-80; 97; 114-116 und passim.

${ }^{36}$ Quanto pecunia dites et voluptatibus opulentos, tanto magis imbellis Aeduos evincite et fugientibus consulite.

${ }^{37}$ Sie waren im Gallischen Krieg Caesars früh auf dessen Seite getreten, stellten Geiseln (Caes. b. Gall. 2,5,1 f.), lieferten Getreide an Caesars Truppen (Caes. b. Gall. 2,9,5) und galten nach den Haeduern als der dem Ansehen nach zweitbedeutendste Stamm in Gallien (Caes. b. Gall. 6,12,7-9). Ihre nach Zerstörung durch die Belger mit Hilfe der Römer neu aufgebaute Hauptstadt Durocortorum/Reims avancierte zur zweitgrößten Stadt in Gallien.

${ }^{38}$ Nach Caesar (b. Gall. 6,13,10) galt das Gebiet der Carnuten gleichsam als Mittelpunkt Galliens, wo sich alljährlich an einem Heiligtum die Druiden trafen, um Streitigkeiten zu schlichten.

${ }^{39}$ Wie auch die Remer verhielten sich die Lingonen während Caesars Krieg in Gallien romtreu und unterstützten Caesar und sein Heer mit Getreidelieferungen (Caes. b. Gall. 1,40,11).

${ }^{40} \mathrm{Zu}$ den ,nationalen' Alen und Kohorten aus dem gallisch-germanischen Provinzgebiet s. die Übersicht von ALFÖLDY 1968, 81-93. Unspezifisch sind in dieser Hinsicht entsprechende Auxilien mit der pauschalen Benennung Gallorum oder Germanorum, die aus mehreren Civitates zusammengestellt wurden. - Aufschlussreich für die Verwendung der nicht tributären Stämme im Kriegsdienst ist die bekannte Bemerkung des Tacitus (Germ. 29,1) zu den Batavern, dass diese nicht durch Tribute erniedrigt oder 
erster Linie zu Tributzahlungen und nicht zur Stellung von Truppen verpflichtet. ${ }^{41}$ Einen Sonderfall bilden die fünf Lingonenkohorten, die nach dem Aufstand der Bataver und Lingonen 69/70 als Strafmaßnahme ausgehoben und vor allem nach Britannien versetzt wurden. ${ }^{42}$ Im Übrigen besitzen wir bislang lediglich drei inschriftliche Zeugnisse von (H)Aedui und von Remi, die offenbar als Freiwillige in verschiedenen militärischen Einheiten gedient haben, jedoch nicht immer in vorflavischer Zeit, in die jedoch zwei Zeugnisse für Lingoni bzw. Lingones datieren. ${ }^{43}$

Umstritten ist die rechtliche Stellung der Treverer gegenüber Rom ${ }^{44}$ insbesondere in julischer Zeit aufgrund der unterschiedlichen Auslegung ihrer Einordnung durch Plinius (n. h. 4,106), in der es heißt: --- Leuci liberi, Treveri liberi antea et Lingones foederati, Remi foederati ---. ${ }^{45}$ Die Zeugnisse für Treveri im römischen Heer sind jedenfalls zahlreicher, und zwar sowohl für einzelne Reiter in verschiedenen Formationen als auch für ,nationale' Einheiten in römischen Diensten. Aufschlussreich ist auch die Dichte an Waffengräbern bei den Treverern aus der Zeit der Eroberung bis Caligula. ${ }^{46}$ Bekannt ist eine ala Treverorum aus der ersten Hälfte des 1. Jahrhunderts. ${ }^{47}$ Diese wird auch jene Ala gewesen sein, welche nach Tacitus (ann. 3,42,1) bei den Treverern ausgehoben worden war, aber bei vereinzelten Ausnahmen ihrer Reiter beim Aufstand 21 Rom treu blieb. Die Rekrutierung der Ala wird etwa in das Jahr 17 datiert. Zu unterscheiden von dieser Einheit ist eine offenbar nach dem Namen ihres ersten Anführers, des Treverers Iulius Indus, benannte ala Gallorum Indiana ${ }^{48}$ Indus kämpfte beim Aufstand 21 anscheinend zunächst als Führer eines nationalen Volksaufgebotes von Treverern erfolgreich gegen seine Landsleute (Tac., ann. 3,40 ff., bes. 3,42,3; 3,46,2), was vermutlich auch auf interne Parteiungen und Rivalitäten um die Vormachtstellung im Stamm zurückzuführen ist. Anschließend wurde diese Formation in eine reguläre Ala umgewandelt und mit Galliern aus anderen civitates ergänzt. Nicht von ungefähr dienten Treverer in der frühen Kaiserzeit bevorzugt in der Reiterei, deren besondere Qualität

durch Steuerpächter ruiniert werden: „Freigestellt von Lasten und Abgaben sind sie nur für den Kampf bestimmt und werden wie Wehr und Waffen für Kriege bereitgehalten"; vgl. auch Tac. hist. 4,12,3; 5,25,2. ${ }^{41}$ WOLTERS 1990, 114 spricht geradezu von einer gewissen „Entmilitarisierung“ von gallischen foederati.

42 Alföldy 1968, 83 mit Anm. 498 f.; Spaul 2000, 176 ff. - Die cohortes I-IV Lingonum mit Standort in Britannien waren beritten, cohors $V$ Lingonum war eine reine Infanterietruppe und ist seit der Wende zum 2. Jahrhundert als Besatzung von Dacien nachgewiesen.

43 (H)Aedui s. CIL XIII 8092 (XIII/4 p. 138) in ala Longiniana (Germ. inf.); AE 1922, 14 in ala Tauriana (Mauretania Ting.); AE 1912, 187 in ala Capitoniana (Moes. inf.). - Remi: CIL XIII 2615 ebenfalls in ala Longiniana; XIII 1844 in legio I Minervia (Germ. inf.); AE 1992, 76 in coh. VII praet. (Roma). Lingoni bzw. Lingones: CIL III 10514 in ala I Hispanorum (Pann. inf.); XIII 7038 in coh. I Belgica (Germ. sup.), jeweils mit der Herkunftsangabe Lingauster. Vgl. auch KRAFT 1951, 21 ff.; HOLDER 1980, 114-118 mit Tab. 8.1 (gallische Rekruten in Hilstruppen der vorflavischen Zeit); ALFÖLDY 1968, 81-87. ${ }^{44} \mathrm{Zu}$ ihnen u.a. WOLTERS 1990, 56-60; 97-100 (zu Caesar, aber auch zur Neuordnung in Gallien unter Augustus 16-13 v. Chr. und zum Census 12 v. Chr.) und passim.

45 WOLTERS 1990, 99 f. schließt auf eine vorübergehende Aberkennung ihres Status als civitas libera gemäß dem Census von 12 v. Chr., den sie aber bald wiedergewann. Andere Forscher beziehen foederati auch auf den aktuellen Rechtsstatus der Treveri, wobei etwa KRIER 1981, 182 diesen Wechsel von civitas libera zu foederata erst um 17 datiert und mit der Aufstellung einer ala Treverorum verbindet. Vgl. auch WOLFF 1977 zum Verhältnis von civitas und colonia der Treverer.

${ }^{46}$ REDDÉ 2008/1, 15. - Dies gilt auch für die Bataver und Bituriger, s. die Karte von Feugère bei REDDÉ (HG.) 1996, 166, wieder abgedruckt bei REDDÉ 2011/2, 72 Abb. 7.

${ }^{47}$ Vgl. zu ihr besonders STEIN (/RITTERLING) 1932, 155 f.; ALFÖLDY 1968, 37 f. und KRIER 1981, 181184.

${ }^{48}$ S. schon Stein (/RITTERLING) 1932, 141 f. und 155 f. - Zu Iulius Indus s. Demougin 1992, $210 \mathrm{Nr}$. 240; BURNAND 2005/10, I 240 (wohl eques Romanus) und II 56 f. Nr. 15 E 43. - Ein civis Trever und eques in dieser Einheit s. CIL XIII 8519 (Worringen. Germ. inf.). 
schon zu Caesars Zeit anerkannt war (Caes. b. Gall. 2,24; 5,2) ${ }^{49}$ Alen und berittene Kohorten aus Gallien spielten im römischen Heer als Hilfstruppen eine wichtige Rolle. ${ }^{50}$

Die Forschung sieht mit unterschiedlicher Akzentuierung teils politische, teils wirtschaftliche Gründe als ursächlich für den Aufstand und beruft sich dabei nicht zuletzt auf aufrührerische Reden, welche nach Tacitus die Rädelsführer in öffentlichen Versammlungen hielten. In diesen beklagten sie die fortdauernden Tribute, die Last der Wucherzinsen $^{51}$ sowie Grausamkeit und Hochmut der Statthalter. Zudem seien nach dem Tod des Germanicus die Soldaten zum Abfall geneigt, äußerst günstig sei der Zeitpunkt zur Wiedergewinnung der Freiheit, wenn sie selbst, in voller Stärke, daran dächten, wie hilflos Italien, wie unkriegerisch das Volk von Rom sei und dass die Stärke der Heere ausschließlich auf Auswärtigen beruhe (Tac. ann. 3,40,3). Wie bereits vermerkt, kann von einem ,nationalen Aufstand' und Freiheitskampf der Gallier jedenfalls nicht die Rede sein. Wie in vergleichbaren Fällen häufig, ist der ideologische und propagandistische Wert der Betonung von Freiheit als erstrebenswertes Ziel zur moralischen Einkleidung von konkreten Interessen ein nützlicher Bestandteil der Agitation. Eine positive Vision für die Zukunft jenseits der Wiederherstellung eines Status quo ist jedenfalls nicht erkennbar. ${ }^{52}$

Die allgemeinen ökonomischen und finanziellen Belastungen für die Provinzbevölkerung insbesondere des zentralen und östlichen Galliens in Folge der Kriegszüge des Germanicus sind von Peter Herz eingehend untersucht und gewürdigt worden. ${ }^{53}$ Nach Velleius Paterculus $(2,39,1)$ zahlen die gallischen Länder nach Caesars Eroberung fast so viel Steuern wie der übrige Erdkreis insgesamt. Den vor dem Trevereraufstand letzten Zensus in Gallien hatte noch Germanicus im Jahr 16 veranlasst (Tac. ann. 2,6,1). Er war schon 14 mit einer Vermögensschätzung in Gallien beschäftigt (Tac. ann. 1,31,2; 33,1). ${ }^{54}$ Die Versorgung der Heere an der Rheinfront erforderte während der Kriegszüge des Germanicus, insbesondere aber auch in Folge derselben mit der daran anschließenden Stationierung umfangreicher Truppenverbände, erhebliche Mittel, die nicht allein vor Ort beschafft werden konnten und auch in der Etappe benötigt wurden. Die Liste der eingeforderten Ressourcen ist lang und umfasst verschiedene Elemente. Dabei handelt es sich um Tribute, Gestellung von Soldaten und Truppenverbänden, Versorgung des Heeres mit Naturalien, Kriegskontributionen, Spann-, Beherbergungsund Arbeitsdienste usw. Zu den üblichen, mehr oder weniger regelmäßig zu leistenden Verpflichtungen gesellten sich als häufig geübte Praxis Ausbeutung und Erpressung der

\footnotetext{
${ }^{49}$ Zum Nachweis von Treveri in anderen Einheiten s. KRIER 1981, passim.

${ }^{50}$ Beabsichtigt ist, weitere Einzelheiten an anderer Stelle zu erörtern.

${ }^{51}$ Diese Praxis führte zusammen mit Geldknappheit auch in Rom selber unter Tiberius zu einschneidenden Maßnahmen seitens des Staates, wie Tacitus (ann. 6,16 f.; vgl. auch Suet. Tib. 48,1; Dio 58,21,4 f.) zum Jahr 33 berichtet.

${ }^{52}$ S. weiter oben mit Anm. 32. - Auf die komplexen Vorstellungen, die Tacitus in verschiedenen Zusammenhängen mit ,Freiheit' (libertas) verbindet, kann hier nur hingewiesen werden.

${ }^{53}$ HERZ 1992 und HERZ 2007, vgl. auch schon ALFÖLDY 1965, bes. 840-842, der nach Meinung von SEAGER 2005, 265 Anm. 169 allerdings in seinem genannten Artikel den Aspekt der Ausplünderung der Provinzen durch Rom übertreibt. Anders aber wieder REDDÉ 2011/1, 506 f., dem Herz ausdrücklich zustimmt.

${ }^{54}$ Strittig ist, ob unter Tiberius Gallien und die primores der Stämme nach Abschluss der Feldzüge in Germanien mit neuen Lasten belegt wurden oder es bei den alten blieb, wie es nach der Formulierung bei Tacitus den Anschein hat. LEVICK 1999, 132-135 verbindet den ökonomischen Druck mit allgemeinen wirtschaftlichen Schwierigkeiten im Reich insbesondere mit Geldnot und periodisch wiederkehrenden Finanzkrisen. Es ist aber nicht zu erkennen, dass die gallische Oberschicht von einem Mangel an finanziellen Ressourcen entscheidend betroffen gewesen wäre, wie DRINKWATER 1978, 817-850 und 1983, 28-30 annimmt. Ähnlich aber auch LEVICK 1999, 133 (aus 1976).
} 
Bewohner zur persönlichen Bereicherung durch die Vertreter der Herrschermacht. ${ }^{55}$ Ambivalent wird diesbezüglich auch die Provinzpolitik des Tiberius selber bewertet, ${ }^{56}$ der auf der einen Seite Repressionen gegenüber den Provinzbewohnern durch Statthalter ungestraft und ohne Wiedergutmachung für die Betroffenen hinnahm oder die Gelegenheit zur eigenen Bereicherung bzw. derjenigen der Staatskasse nutzte. ${ }^{57}$ Andererseits werden Gegenbeispiele häufig indirekt verbunden mit einer Tiberius zugeschriebenen Sentenz in einem Brief an den Präfekten von Ägypten: „Ein Hirte erweist sich als guter Hüter, wenn er das Vieh (sc. die Schafe) schert und nicht häutet" (Suet. Tib. 32,2; vgl. Dio 57,10,5). Da es jedoch auch nicht an Anklagen wegen ungerechtfertigter Bereicherung der Bevollmächtigten Roms in den Provinzen fehlte, kann dies zugleich als Beleg dafür gelten, dass die Order des Tiberius nicht allenthalben befolgt wurde. ${ }^{58}$ Dies ist auch indirekt aus den lobenden Worten des Philo (Flacc. 105) zu schließen, der anmerkt: ,Erpressung war weit verbreitet, aber Tiberius tat sein Bestes, dies zu bestrafen. “ Im Übrigen wird dem Princeps nicht ohne kritischen Unterton (Geiz) altrömische Sparsamkeit (antiqua parsimonia) unterstellt (Tac. ann. 3,52,2; vgl. auch Suet. Tib. 34,1; 46: pecuniae parcus ac tenax). Mit deutlicher Missbilligung vermerkt Sueton (Tib. 48,1), dass von Seiten des Princeps lediglich zweimal eine großzügige finanzielle Unterstützung der Allgemeinheit (munificentia) erfolgte. Dies bezieht sich auf Rom. In einem Brief an den Senat im Jahr 22 stellte Tiberius unmissverständlich den Vorrang von Rom und Italien gegenüber den Provinzen heraus, ${ }^{59}$ jedoch leistete Tiberius auch finanzielle Hilfe bei Katastrophen im Reich. ${ }^{60}$ Nur sehr selten wiederum profitierten aber die Provinzen und ihre Bewohner von Bürgerrechtsverleihungen und Urbanisierungsmaßnahmen.

Der Verlauf des Aufstandes des Florus und Sacrovir kann kurz abgehandelt werden. Nach Tacitus (ann. 3,41,1) blieb kein Stamm Galliens von der Aufstandsbewegung unberührt, zweifellos eine Übertreibung der tatsächlichen Verbreitung der Erhebung.

\footnotetext{
${ }^{55} \mathrm{Zu}$ diesbezüglichen ,Techniken`vgl. etwa den Friesenaufstand des Jahres 28. Tacitus (ann. 4,72,1) vermerkt dazu, dass sich die Friesen mehr wegen der römischen Habsucht als aus Verweigerung des Gehorsams (nostra magis avaritia quam obsequii inpatientes) erhoben, denn der Tribut, den ihnen Drusus auferlegt hatte, war mäßig. - Vergleichbare Zustände und Klagen durch die einheimische Bevölkerung in Britannien beschreibt Tacitus für die Zeit der Statthalterschaft des Iulius Agricola, s. Tac. Agr. 19,4 und 31,1-3.

${ }^{56}$ S. bes. ALFÖLDY 1965 mit ausführlicher Quellenkritik und besonderem Fokus auf die in mancher Hinsicht negativen wirtschaftlichen Folgen der Politik des Princeps gegenüber den Provinzbewohnern.

${ }^{57}$ Vgl. etwa Sen. ep. 1,12,8 zu Pacuvius, Legionslegat und wohl als vice legati Syriae für den in Rom verweilenden C. Aelius Lamia in Syria verantwortlichen Stellvertreter (PIR ${ }^{2}$ P 46). Aufschlussreich besonders Tac. ann. 4,19 f. zum Verfahren gegen C. Silius, Legat in Germania superior, im Jahr 24, dem u.a. Habgier (avaritia) und zusammen mit seiner Gattin erpresserische Bereicherung vorgeworfen wurde (nec dubie repetundarum criminibus haerebant - ann. 4,19,42). Den folgenden Teileinzug des Vermögens kommentiert Tacitus (ann. 4,20,2): „Dies war der erste Fall, dass Tiberius sich um fremdes Geld sorgte." Aus späterer Zeit s. Tac. ann. 6,2,1 (Vermögen des Seian) und bes. Tac. ann. 6,19 f. (mit Dio $58,22,2$ ) zum gewaltsamen Tod von Sex. Marius, dem reichsten Mann Hispaniens, und Beschlagnahme von dessen Gold- und Silberbergwerken in der Baetica zu eigenem Besitz. Allgemein zum Verhalten gegenüber begüterten Familien in Rom sowie den principes der Provinzen, insbesondere auch Galliens, Suet. Tib. 49.

${ }^{58} \mathrm{Vgl}$. BRUNT 1961, 189 f. und 200 ff. mit Appendices.

${ }^{59}$ Tac. ann. 3,54,4 zur Bedeutung der provinciarum copiae für Rom und Italien: „Aber beim Hercules! Niemand verweist darauf, dass Italien auswärtiger Hilfe bedarf, dass das Leben des römischen Volkes täglich von den Ungewissheiten des Meeres und der Stürme umhergetrieben wird." S. dazu etwa GELZER 1919, 528 und ALFÖLDY 1965, 840-842.

${ }^{60}$ Tac. ann. 2,47 f.: Unterstützung der von einem Erdbeben betroffenen Städte in Kleinasien im Jahr 17 sowie 6,45,1: Brandfolgen in Rom. Liberalitas insbesondere gegenüber der Nobilität und Schonung von deren Vermögen gegen Einvernahme durch den Fiscus lobt Tacitus (ann. 2,48). Auch dies betrifft in erster Linie Rom als Zentrum und die aristokratische Oberschicht.
} 
Die Gerüchteküche in Rom dramatisierte allerdings die reale Gefahr und mutmaßte den Abfall aller Stämme Galliens sowie ein Bündnis mit den Germanen, zudem seien die hispanischen Länder wankend (Tac. ann. 3,44,1). ${ }^{61}$ Offenbar blieb aber die große Mehrheit der primores Galliae und selbst derjenigen der am Aufstand beteiligten Stämme Rom treu. Wie sich zeigen sollte, wurde die Erhebung vergleichsweise schnell und mit begrenztem Einsatz der römischen Streitkräfte niedergeschlagen. Zum Ausbruch kam der Aufstand zunächst bei den Andecavi (um Angers) und Turoni (um Tours), die aber durch die in Lugdunum/Lyon stationierte römische Kohorte und durch die Heranführung von Legionssoldaten aus dem niedergermanischen Heer in die Schranken gewiesen wurden. Schwieriger war die Ausgangslage für Rom in Bezug auf die Treveri und (H)Aedui. Erstere wurden durch eine Vexillation von Legionären aus beiden Germanien, letztlich aber bereits durch eine vorausgeschickte Schar ausgewählter Reiter unter Führung des bereits weiter oben erwähnten Iulius Indus, eines Stammesgenossen und Rivalen des Florus, auseinandergetrieben (Tac. ann. 3,42). ${ }^{62}$ Die Heeresstärke der Haeduer gibt Tacitus mit 40000 Mann an, von denen etwa 8000 mit Legionswaffen ausgerüstet waren, der Rest aber durchweg lediglich mit Jagdwaffen. Den Kern dürfte eine Miliz gebildet haben, ${ }^{63}$ jedenfalls kein regulärer römischer Hilfstruppenverband, zudem musste die iuventus in Augustodunum erst mit heimlich gefertigten Waffen ausgerüstet werden. $\mathrm{Zu}$ diesen Bewaffneten kamen noch für den Gladiatorenkampf vorgesehene Sklaven ${ }^{64}$ hinzu sowie Truppen aus benachbarten Stämmen (Tac. ann. 3,43). Aber das energische Eingreifen des Kommandanten des obergermanischen Heeres, C. Silius ${ }^{65}$, mit zwei Legionen und Hilfstruppen brachte rasch die Entscheidung zugunsten der Römer (Tac. ann. 3,45 f.), so dass Tiberius dem Senat schrieb, der Krieg habe begonnen und sei (zugleich) beendet worden (Tac. ann. 3,47,1: ortum patratumque bellum senatui scripsit). Velleius Paterculus vermerkt gegen Ende seines Werkes in gewohnt rhetorischer Übertreibung: ,Welch gewaltigen Krieg, den der Gallierfürst Sacrovir zusammen mit Iulius Florus begonnen hatte, hat er (Tiberius!) mit solch unglaublicher Schnelligkeit und Virtus niedergeschlagen, dass das römische Volk eher von dem Sieg als von dem Krieg selbst erfuhr und die Siegesnachricht die Gefahrenmeldungen überholte“ (2,129,3: ... ut ante populus Romanus vicisse se quam bellare cgnosceret nuntiosque periculi victoriae praecederet nuntius). ${ }^{66}$ Aus archäologischer Sicht können möglicherweise zwei Lager der Römer mit dem Aufstand 21 in Verbindung gebracht werden: zum einen Aulnay-de Saintonge (Aunedonnacum) an der Grenze der Territorien der

\footnotetext{
${ }^{61}$ Auch Tacitus wertet dies allerdings als Bestandteil üblicher Gerüchte, die in Rom in derartigen Lagen des Staates gestreut zu werden pflegten. Dabei mag auch einmal mehr der traditionelle metus Gallicus instrumentalisiert worden sein, bei dem Furcht und Überlegenheit in eins flossen und der nur vom furor Teutonicus (Luc. 1,255) übertroffen wurde. Jedoch werden im Bericht des Historikers seinem besonderen Interesse entsprechend die Ereignisse und ihre Beurteilung in der Öffentlichkeit mit innerpolitischen Aspekten der Herrschaftspraxis des Tiberius verwoben. Dabei hebt er aber auch die Gelassenheit des Tiberius gegenüber der tatsächlichen Gefahr und den diesbezüglichen Gerüchten hervor, vgl. Tac. ann. $3,44,2-4$.

${ }^{62}$ S. 9 mit Anm. 48.

${ }^{63}$ Nach Tac. ann. 3,43,1 hatte Florus den Hauptort des Stammes mit armatae cohortes besetzt.

${ }^{64}$ Sie trugen nach Stammessitte ein durchgehendes Eisengewand und wurden crupellarii genannt, im Folgenden spricht Tacitus von ferrati (ann. 3,43,2 mit 3,46,3).

${ }^{65}$ Er wurde 24 in Rom angeklagt, weil er angeblich in Kenntnis der Kriegsgefahr die Bedeutung des Sacrovir verschwiegen habe (Tac. ann. 4,19,4), eine wohl vorgeschobene und sachlich kaum haltbare Anschuldigung.

${ }^{66}$ Dankfeste und weitere Ehrungen durch den Senat sowie den „läppischen Vorschlag“ (GELZER 1919, 507) einer Ovatio wies Tiberius mit Verweis auf seine früheren, größeren Erfolge kaum überraschend zurück (Tac. ann. 3,47,3 f.).
} 
Santonen und Pictonen, ${ }^{67}$ zum anderen Arlaines (Pontarcher) an der Aisne, westl. von Soissons ${ }^{68}$ Michel Reddé gelangt aber bezüglich der Schwere und Tragweite des Aufstandes $21 \mathrm{zu}$ dem Schluss: „,... il est clair [---] que la répression de l'insurrection a été moins facile que ne le suggère le récit de Tacite, et que la révolte a eu des conséquences à relative long terme: le camp d'Arlaines est en effet occupé, apparemment, sans interruption, jusque vers les années $80 . " 69$

\section{Das römische Heer und die Rheinfront unter Tiberius - Aspekte der Heeres- geschichte}

Im Bericht des Tacitus zum Jahr 23 über die römischen Schutztruppen am Rhein überrascht zunächst der Hinweis auf die strategische Ausrichtung der Armee, deren Funktion als subsidium in Germanos Gallosque, also Abwehrstellung gleichermaßen gegen Germanen wie Gallier charakterisiert wird. Tacitus lässt keine Zweifel, dass die folgenden Ausführungen und Formulierungen trotz des Bezugs auf die Einlassungen des Princeps auf eigene Zusammenfassung und mithin auch Einschätzung zurückgehen und damit allenfalls sekundär auf Tiberius selber (Tac. ann. 4,4,3-4,5 mit den weiteren Ausführungen zur Staatsverwaltung in 4,6). ${ }^{70}$ In das Urteil können somit auch über die unmittelbare Vorgeschichte zum Jahr 23 mit der Erhebung der Gallier unter Florus und Sacrovir im Jahr 21 hinaus Erfahrungen aus früherer wie späterer Zeit Eingang gefunden haben, wie Ereignisse im gallischen Großraum in der Zeit des Augustus oder etwa auch der Aufstand der Bataver und Lingonen 69/70. Allerdings kann dieses allenfalls vermutet werden. Dennoch ist wenigstens im Kern von einem engeren sachlichen $\mathrm{Zu}$ sammenhang und somit auch einem mindestens in Teilen prekären Verhältnis zwischen dem ostgallischen Raum und der römischen Rheinfront in der Zeit des Tiberius nach Aufgabe der Offensivkriege auszugehen. Aber selbst wenn man von der provincia Gallia Narbonensis absieht, ist ein pauschaler Bezug auf den gesamten Bereich der Gallia Comata unwahrscheinlich, zumal in diesem Großraum seit den Eroberungszügen Caesars der Rhythmus der Integration, Urbanisierung und Assimilierung an die Kultur des Mittelmeerraumes nach Zeit und Intensität ganz verschieden verlief. Dies musste sich entsprechend auch auf die Beziehungen zwischen Rom und den Provinzbewohnern auswirken. Worauf könnte aber das Gefährdungspotential beruhen und welche Art von Konflikten mochten den Frieden in Gallien bedrohen, so dass die vor allem im Grenzbereich zu Germanien stationierten römischen Truppen gleichsam janusköpfig in strategischer Bereitschaft gegen Germanien wie Gallien standen? Strabo schreibt den Galliern zwar generell große Kriegslust und militärisches Potential zu, doch sei dies in vergangenen Zeiten genutzt worden, während sie jetzt alle in Frieden leben würden,

\footnotetext{
${ }^{67}$ REDDÉ 1987, 347-350 mit 349 Abb. 3a. b; REDDÉ 1991, 44-46; vgl. die Inschriften CIL XIII 11211123 (XIII/4 p. 10).

${ }^{68}$ REDDÉ 1987, 357-360 mit 358 Abb. 9 und der Folgerung: „Un datation tibérienne serait possible et apparemment préferable, mais ne peut être assure“ (359). Vermutet wird, dass sich hier das Lager der ala Vocontiorum befand (CIL XIII 3463), die wegen des Umfangs des Kastells möglicherweise als ala milliaria anzusehen sei. S. ferner REDDÉ 1991, 43 f. Das Lager scheint erst in spätflavischer Zeit aufgegeben worden zu sein.

${ }^{69}$ REDDÉ 1987, 368. Ob der Aufstand 21 aber der maßgebende Grund für das Fortbestehen des Lagers war, bleibt unseres Erachtens fraglich.

${ }^{70}$ Tacitus betont, dass er als Historiker diese Gelegenheit für eine eigene Übersicht über die Positionierung von Schutztruppen zu Lande und zu Wasser im gesamten Reich unter Einschluss von Rom und Italien wahrnehmen will. Dabei fehlt auch nicht ein pauschaler Hinweis auf Flottenverbände (Dreiruderer), Alen und Kohorten an geeigneten Plätzen in den Provinzen.
} 
nachdem sie unterworfen (,versklavt“" $\left.-\delta \varepsilon \delta o v \lambda \omega \mu \varepsilon^{\prime} v o l\right)$ worden seien und nunmehr in Übereinstimmung mit Roms Befehlen leben würden. ${ }^{71}$ Der Trevereraufstand des Jahres 21 liefert zwar einige Hinweise zum Verständnis der strategischen Ausrichtung des römischen Militärs an der Rheinfront, veranlasst aber auch durch Einbindung in einen größeren historischen Kontext zu einigen weiteren Überlegungen zur Militärgeschichte Roms in Gallien nach Caesar bis in die spätaugusteische und tiberische Zeit. Dabei kann es sich nur um einige ausgewählte und in unserem Zusammenhang für relevant erachtete Aspekte handeln.

Caesars Eroberung Galliens hatte im Jahr 51 v. Chr. zwar ein besiegtes, nicht aber befriedetes oder gar verwaltungsmäßig erschlossenes Gebiet hinterlassen. ${ }^{72}$ Bürgerkriege und drängende Ereignisse an anderen Fronten des Imperiums bestimmten in der Folgezeit den politischen und militärischen Alltag in Rom. Vorgänge im Inneren Galliens fanden daher nur gelegentlich das Interesse der Berichterstatter, so dass die diesbezügliche Quellenlage spärlich und lückenhaft ist. Dies spiegelt auch die aktuelle Forschungslage wider, bei der jedoch zumindest dahingehend weitgehend Einigkeit zu bestehen scheint, dass der Übergang von der protohistorischen zur historischen Epoche in Gallien im Zuge der caesarischen Eroberungskriege weniger einen Bruch in den Zivilisationsstrukturen zur Folge hatte als vielmehr die Initiierung evolutionärer Prozesse. Nach Caesar umschloss Gallia omnis das zentrale Gallien ohne die Transalpina und erst recht nicht die Cisalpina (b. Gall. 1,1; vgl. Mela 3,20 und Plin. n. h. 4,105: Gallia omnis Comata; anders Strab. 4,1,1=177 C). Mindestens bis ins Jahr 27 v. Chr. wurde dieses Gallien unter der Bezeichnung Gallia Comata als Einheit begriffen. Wann die endgültige administrative Aufteilung in die drei Provinzen Aquitania, Lugdunensis und Belgica erfolgte und wie genau jeweils der territoriale Zuschnitt war, ist bis heute strittig, ${ }^{73}$ wenngleich der Aufenthalt von Augustus in Gallien zwischen 16 und 13 v. Chr. hierfür allgemein als der wahrscheinlichste Zeitpunkt gilt. Jedenfalls entsprach die neue Dreiteilung nicht derjenigen Caesars auf ethnischer Grundlage (b. Gall. 1,1). Bereits $22 \mathrm{v}$. Chr. war die schon vor mehr als einhundert Jahren gegründete und stark römisch geprägte Provinz Narbonensis als eigenständiger Raum unmittelbar senatorischer Verwaltung unterstellt worden, welche der Senat durch einen jährlich aus seinem Kreis gewählten proconsul ausübte. Die Verantwortung für die übrigen Provinzen Galliens einschließlich der germanischen Heereszonen oblag dem Princeps. Aber noch im Jahr 48 fasste Kaiser Claudius in seiner berühmten Rede über die Verleihung von Ehrenstellen an Gallier diesen Großraum als Gallia Comata zusammen (CIL XIII $1668=$ ILS 212 = AE 1983, 693; vgl. Tac. ann. 11,23-25). ${ }^{74}$ Insgesamt ergab jedoch die räumliche und stammesmäßige Neuorganisation der Völkerschaften Galliens als civitates

\footnotetext{
${ }^{71}$ Strab. 4,4,2 = 195 C.

${ }^{72}$ Nach Caes. b. Gall. 8,54,4 f. (Hirtius) hatte Caesar bei seiner Rückkehr nach Rom acht Legionen in Gallien belassen, von denen er vier im Gebiet der Belger (vgl. auch Caes. b. Gall. 8,49) und die anderen vier bei den Haeduern stationierte, um so Gallien am besten sichern zu können. Auf diese Weise würden die Belgae als die die Tapfersten (maxima virtute) und die Haedui als die Einflussreichsten (auctoritate summa) durch die Heere in Schranken gehalten. - Zu einigen archäologisch der caesarischen oder frühaugusteischen Zeit zuzuschreibenden militärischen Anlagen unterschiedlicher Größe und dementsprechend auch unterschiedlicher Funktion s. neben dem im Treverischen vor einigen Jahren entdeckten Hermeskeil die eingehenden Diskussionen des Forschungsstandes zu verschiedenen Plätzen bei REDDÉ 1987, REDDÉ 2008/1; REDDÉ 2008/2; REDDÉ 2009; REDDÉ 2011/2 und in weiteren Publikationen, s. hier im Literaturverzeichnis.

${ }^{73}$ Vgl. etwa Strab. 4,3,1-3 = 176-179 C und die weiteren Mitteilungen bei ihm im vierten Buch. Dazu GOUDINEAU 1990. Die Nachrichten sind nicht immer einfach mit den geographischen Gegebenheiten in Einklang zu bringen. Zudem ist mit Veränderungen in der Zuordnung der Gebiete zu rechnen.

${ }^{74}$ Zur Rede vgl. RIESS 2003 und zuletzt JAKOBSMEIER 2018.
} 
mit unterschiedlichen Rechtsformen und damit auch unterschiedlichen Rechtsbeziehungen zu Rom ein differenziertes Bild gegenüber einer einheitlichen Gallia Comata, was gleichermaßen für die unterschiedlichen Siedlungs- und Bevölkerungsstrukturen gilt. ${ }^{75}$ Eine politische und symbolische Klammer war der wohl 12 v. Chr. von Drusus d. Ä. dedizierte Altar der Tres Galliae für Roma et Augustus bei Lugdunum/Lyon (Condate) mit Tempel und Amphitheater. An diesem ,Bundesheiligtum‘ feierten die Abgeordneten der ca. 60 gallischen Civitates jährlich am 1. August ein Fest, und hier tagte dann auch der Landtag dieser Gemeinden. ${ }^{76}$ Es war in erster Linie ein politisches Instrument Roms und zielte vor allem auf die Einbindung der Führungsschichten der Civitates in die imperiale Gemeinschaft. Ein ähnlich integrierendes Element war zweifellos der Kaiserkult in den verschiedenen Gemeinden, aber auch lateinische Sprache und römisches Recht trugen zu einer gewissen ,Romanisierung/Romanisation ' und damit zur Konstituierung einer gallo-römischen Bevölkerungsstruktur bei. Die daraus folgenden Konsequenzen sind jedoch hinsichtlich Wirkung und Abläufen ebenso differenziert zu beurteilen wie generell die kulturellen, ökonomischen, politischen und militärischen Aspekte. Dazu zählt auch die Heeresgeschichte Roms in Gallien insbesondere im Zeitraum von Caesar bis in die frühe Phase des Principats, wobei sich nicht zuletzt angesichts der Quellenlage vorschnelle Verallgemeinerungen von punktuellen Erkenntnissen verbieten. Trotz beachtlicher Fortschritte insbesondere aufgrund der archäologischen Forschungen der letzten ca. 40 Jahre und der Auswertung weiterer Funde wie von Inschriften und Münzen sind viele Fragen zur Stationierung römischer Verbände oder zu strategischen und taktischen Dispositionen nach wie vor ungeklärt. ${ }^{77}$ Es ist an dieser Stelle aber weder beabsichtigt noch möglich, die kaum mehr überschaubare Spezialliteratur zu den militärischen Anlagen und zur Dislokation der verschiedenen militärischen Einheiten auch nur annähernd umfassend aufzuarbeiten, jedoch soll zumindest auf einige Zusammenhänge und Prozesse - basierend unter anderem auf jüngeren Erkenntnissen - aufmerksam gemacht werden. ${ }^{78}$

\footnotetext{
${ }^{75}$ Zur Frage der Kontinuität zwischen keltischen Territorien und gallo-römischen Civitates vgl. etwa TARPIN 2006.

${ }^{76}$ Zum nach wie vor umstrittenen genauen Datum der Einweihung des Altars s. die Diskussion bei FISHWICK 1996 mit den nicht leicht zu harmonisierenden Angaben in den Quellen. Fishwick entscheidet sich erneut für $12 \mathrm{v}$. Chr., ohne sich auf einen genauen Tag festzulegen. - $\mathrm{Zu}$ den provinzialen Landtagen und ihrer Funktion grundlegend DEININGER 1965.

${ }^{77}$ Die lange Zeit grundlegende Untersuchung von RITTERLING 1906 zur Heeresgeschichte in Gallien ist heute weitgehend überholt.

${ }^{78}$ Als Ausgangspunkt der aktuellen Forschungen zum römischen Gallien sind nach wie vor die Studien von WIGHTMAN 1974 und 1977 von Bedeutung, auch wenn einige grundlegende Annahmen wie die enge Verbindung von größeren Komplexen an Terra sigillata mit der Stationierung von römischen Truppen, die schon RITTERLING 1906 postulierte, heute in Frage gestellt und wesentlich differenzierter beurteilt wird. Dasselbe gilt für die Aussagefähigkeit von keltischen Münzen als Hinweis auf die Stationierung von Hilfstruppen, wie etwa FURGER-GUNTI 1981 annahm, s. dazu WOLTERS 1998. Wightman beklagte aber zu Recht die zu ihrer Zeit beschränkten archäologischen Aufschlüsse, was sich seither deutlich verbessert hat, ohne dass die diesbezügliche Forschung an ihr Ende gelangt wäre. Zur aktuellen Diskussion über die Geschichte Galliens vor allem in der Phase der Begegnung mit Rom seit Caesar bis Tiberius s. etwa GOUDINEAU 1990 und 1996; WOLTERS 1990 und 2001; RAEPSAET-CHARLIER 1998; FICHTL 2000; BÜCHSENSCHÜTZ 2004; FERdiÈRE 2005; PAUNIER (HG.) 2006; RedDÉ 2008/1 sowie die grundlegende Studie von WoOLF 1998. Für den französischen Anteil des antiken Gallien sind auch die verschiedenen Faszikel der Carte Archéologique de la Gaule (CAG) zu vergleichen. - Zu den militärischen Aspekten, insbesondere den entsprechenden Anlagen in Gallien, aber auch teilweise an der Rheinfront, und der Frage der Stationierung römischer Truppen s. insbesondere REDDÉ 1987 und seine verschiedenen Beiträge aus den folgenden Jahren, s. dazu hier im Literaturverzeichnis. Ferner sind besonders erwähnenswert Metzler 1995 sowie die Beiträge in LE BoHeC (HG.) 1993, RedDÉ (Hg.) 1996 und 2009 oder PouX
} 
Landläufiger Ansicht zufolge richtete sich die Frontstellung der römischen Armee an Rhein und Donau ab augusteischer Zeit in erster Linie gegen die Bewohner der Germania magna und die von dort ausgehenden Unruhen, die teilweise weit nach Gallien hinein reichten. ${ }^{79}$ Die politische und militärische Abgrenzung der Germania magna zum generell, wenngleich pauschal, als zivilisierter eingestuften Gallien durch den Rhein war vor allem Caesar zu verdanken, der diese eingängige Grenzscheide etwas formal, wenngleich nicht völlig willkürlich, für die Folgezeit gleichsam festgeschrieben hat. ${ }^{80}$ Sie hatte zuvor in dieser Form keinen Bestand, da der Rhein weder eine ethnische Grenze markierte noch mehr oder weniger intensive politische und wirtschaftliche Wechselbeziehungen zwischen den Bewohnern beiderseits des Stroms ausschloss. Nach Konsolidierung der Herrschaftsverhältnisse in Rom verstärkten die Principes durch verschiedene Maßnahmen die Vorstellung von einem Grenzcordon im östlichen Gallien, welcher dann durch die Errichtung der beiden Heeresbezirke in Ober- und Untergermanien und ihre gesonderte militärische Verwaltung auch deutlich markiert wurde. Bei der zivilen Verwaltung, insbesondere der Finanzverwaltung, blieb bekanntlich der Zusammenhang der Heeresbezirke mit Gallien gewahrt.

Eine deutliche Form der Abgrenzung zum großgermanischen Raum erfolgte jedoch auch durch die sich über einen längeren Zeitraum erstreckende, aber erst nach Caesar teils gewaltsam, teils freiwillig durchgeführte Ansiedlung germanischer Stämme auf der linken Seite des Rheins, aber auch durch die Aufnahme einiger Völkerschaften im Grenzbereich in die Schutzgemeinschaft Roms. Dies betraf etwa Friesen, Caninefaten, Bataver, Ubier, Sugambrer/Cugerner im nördlichen sowie Vangionen, Nemeter und Tribocer im südlichen Bereich des Flussverlaufs. Einige dieser Stämme standen allerdings schon seit längerem in enger Beziehung zum keltischen Kulturkreis. Die veränderte Strategie Roms verfolgte zum einen das Ziel, die mehr oder weniger unkontrollierte Fluktuation über den Fluss hinweg einzudämmen und insbesondere das mittlere und östliche Gallien vom Druck der wiederholt aus dem Bereich der Germania magna auf der Suche nach Siedlungsland andrängenden oder auf rasche Beute erpichten Scharen zu entlasten. ${ }^{81}$ Nicht selten wurden diese aber auch in innergallische Unruhen auf Grund dort rivalisierender Adelsfraktionen oder von Stammeskämpfen hineingezogen. ${ }^{82}$ Zum anderen verfolgte die Ansiedlung den Zweck der Beteiligung dieser Völkerschaften an der Grenzsicherung: ut arcerent non ut custodirentur, wie Tacitus später zu den Ubiern ausdrücklich vermerkt (Germ. 28,4). ${ }^{83} \mathrm{In}$

(HG.) 2008. - Speziell zu den militärischen Anlagen am Rhein baut die aktuelle Forschung auf der grundlegenden Zusammenfassung und eingehenden Diskussion bei SCHÖNBERGER 1985 auf, s. auch weiter unten.

${ }^{79} \mathrm{Vgl}$. auch Jos. b. Iud. 2, $376 \mathrm{f}$.

${ }^{80}$ Vgl. etwa Strab. 4,3,4 = 193 f. C; 4,4,2 = 196 C; 7,1,1-5 = 289-292 C usw.; Mela 3,3,25; Tac. Germ. 1,1 .

${ }^{81}$ Grundsätzlich gehörten mehr oder weniger freiwillig akzeptierte oder aber auch erzwungene Um- und Ansiedlungsaktionen zum Zweck der Pazifizierung und besseren Kontrolle von Bevölkerungsgruppen schon in republikanischer Zeit zu den häufig praktizierten militärischen und politischen Maßnahmen. Auch im südwestlichen Bereich Galliens spielten Siedlungsvorgänge unter römischer Obmacht eine Rolle wie etwa in Bezug auf die Vivisci, die im Mündungsgebiet der Garonne um Burdigala/Bordeaux Siedlungsland erhielten.

${ }^{82}$ TIMPE 1975, 124-147 = 2006, 147-170 zur Geschichte der Rheingrenze zwischen Caesar und Drusus. ${ }^{83}$ WOLTERS 2001; HEINRICHS 2001; REDDÉ 2008/1, 12 f. - Diese unmittelbar auf die Ubier gemünzte Aussage ist in ihrem Kerngehalt sicherlich nicht einseitig nur auf diesen Stamm zu beziehen, s. besonders auch Tac. Germ. 29,1 zu den Batavern, dazu Roymans 2004, passim. Auf die strittige Datierung verschiedener Umsiedlungsaktionen, die sich nicht in einem Akt abspielten, kann hier nicht näher eingegangen werden. Sie erfolgten jedenfalls in nachcaesarischer Zeit und waren Konsequenz einer teilweise veränderten Strategie gegenüber den Völkerschaften vor allem im rechtsrheinischen Barbaricum. Für die 
tiberischer Zeit erlaubte oder förderte Rom sogar die Ansiedlung swebischer Siedlerscharen entlang der östlichen Uferzonen von Mittel- und Oberrhein. ${ }^{84}$ Diese aktive Politik an der Rheinfront und im östlichen Gallien wirkte sich notwendigerweise auf die Raumordnung sowohl im Grenzbereich zwischen Gallien und Germanien als auch bis tiefer ins Innere Galliens aus, zumal traditionelle Stammesgebiete wie etwa diejenigen der Helvetier, Mediomatriker, Treverer und Nervier von der römischen Ansiedlungspolitik neuer Stammesverbände betroffen waren.

Auf das Vorgehen Roms im Bereich der Germania magna und die verschiedenen Stützpunkte, welche seit den Feldzügen des Drusus 12 v. Chr. im Inneren dieses Raumes vom römischen Heer gegründet, aber spätestens nach der Varus-Niederlage wieder aufgegeben wurden, braucht an dieser Stelle nicht weiter eingegangen zu werden. Dagegen ist es angesichts der Einlassung des Tiberius bzw. des Tacitus vor dem Senat im Jahr 23 angebracht, der Einflussnahme des römischen Militärs auf die Geschicke in Gallien seit Caesar und ab dem Principat des Augustus etwas genauer nachzugehen und in diesem Zusammenhang auch den Prozess der Truppenkonzentration entlang des Rheins in einigen wichtigen Grundzügen zu bedenken. Seit mehreren Jahren hat sich Michel Reddé besonders intensiv und auch kritisch mit den Erkenntnissen zum römischen Militär und den diesbezüglichen Zeugnissen in Gallien aus der fraglichen Epoche auseinandergesetzt. Die von ihm zu Recht wiederholt mit der gebotenen Vorsicht als ,vorläufig“ eingestuften Ergebnisse zur militärischen Besetzung dieses Raumes bilden auch eine wichtige Grundlage für die folgende Übersicht.

Für die Ereignisgeschichte der Gallia comata unter besonderer Berücksichtigung der Einflussnahme Roms und des römischen Militärs nach Caesar liefert die erste Statthalterschaft des M. Vipsanius Agrippa in Gallien 39/38 v. Chr. als Nachfolger des Salvidienus Rufus erste Hinweise. Da Agrippa 20/19 v. Chr. erneut Gallien verwaltete, ist die Forschung uneins bezüglich der Frage, welche Maßnahmen im Einzelnen der ersten oder der zweiten Statthalterschaft zuzuordnen sind. In die frühere gehören jedenfalls ein Rheinübergang (an unbekannter Stelle und mit unbekanntem Ziel), der erste nach den beiden von Caesar 55 und 53 v. Chr. unternommenen, sowie ein erfolgreicher Kampf gegen aufständische Aquitanier im Südwesten Galliens. ${ }^{85}$ Der Aufenthalt Agrippas im Osten Galliens dürfte auf Unruhen in diesem Bereich hinweisen, vielleicht bei den Treverern, wie ein Jahrzehnt später, als es bei den Treveri und Morini zu einem Aufstand gegen Rom unter Zuzug germanischer Scharen kam. Dieser wurde durch den

Ubier ist diese Maßnahme in jedem Fall mit Agrippa zu verbinden. Ob die Aktion aber in dessen erster Statthalterschaft in Gallien 39/38 v. Chr. oder in seiner zweiten 20/19 v. Chr. erfolgte, wird weiterhin kontrovers diskutiert.

${ }^{84}$ Nach aktuellen Erkenntnissen erfolgte die Besiedlung von Gebieten um Groß-Gerau, Ladenburg und Diersheim b. Offenburg durch swebische Scharen im Wesentlichen in einem Zug unter Tiberius, was einen politischen Willen seitens der römischen Reichsregierung unterstreicht. Die frühere Forschung ging von einer sich über Jahrzehnte erstreckenden Besiedlung durch Sweben von Nord nach Süd aus. Grabungen der jüngeren Vergangenheit bei Diersheim belegen aber auch für die Oberrheinsweben ihre Ansiedlung bereits in tiberischer Zeit, s. etwa SCHREMPP U.A. 2015 und 2016.

${ }^{85}$ App. b. c. 5,92; Eutr. 7,5; Suet. Aug. 21,2; vgl. Dio 48,49,3: Sieg über rebellische Gallier, wobei aber fraglich ist, welche Stämme hier genauer gemeint sind, zumal Dio in diesem Zusammenhang auf den zweiten Rheinübergang des Agrippa verweist. Aquitanien war zur Zeit Caesars vor allem unter Vercingetorix' Führung Ausgangspunkt erbitterten Widerstandes gegen Rom gewesen. Etwa ein Jahrzehnt nach Agrippas Erfolg musste M. Valerius Messalla (Corvinus) erneut gegen rebellierende Aquitanier vorgehen, die er besiegte. Für den Erfolg wurde er mit einem Triumph belohnt (App. b. c. 4,38; Tibull. 1,7,3 12; 2,1,33), vgl. zu Person und Karriere PIR ${ }^{2}$ V 143 mit den Quellen. REDDÉ (1987, 352 mit Anm. 29 und 2009, 177 f.) hält die Verbindung dreier Soldatengrabsteine (CIL XIII 922-924) aus Aginnum/Eysses b. Villeneuve-sur-Lot (Aquitania) mit dem Feldzug des Messalla für denkbar, aber es fehlen am Ort entsprechende Bodenzeugnisse für ein Lager. 
Legaten des Augustus, L. Nonius Gallus, und den Proconsul Galliens, C. Carrinas, niedergeschlagen. ${ }^{86}$ Damals wurde offenbar das ca. 50 ha umfassende Lager auf dem Petrisberg b. Trier im Zentrum der Treverer, aber in Verteidigungslage, errichtet. ${ }^{87}$ Es ist eines der bislang frühesten archäologisch nachweisbaren Zeugnisse für die Anwesenheit römischer Truppen in Ostgallien nach Caesar in einer über längere Zeit als einen Sommer genutzten Militärbasis. Im Zusammenhang mit diesem Trevereraufstand 30/29 v. Chr. wurde jedoch auch eine römische Militärstation im Bereich des keltischen Oppidums auf dem Titelberg (Luxemburg), also gleichfalls auf einer Höhe und somit in Verteidigungslage, angelegt. ${ }^{88}$ Bemerkenswert ist die Abgrenzung zwischen indigener Bevölkerung und den Bauten des Militärs, bei denen es sich möglicherweise um Vorratsgebäude handelt. Die Situation bietet aber gewissermaßen ein ,klassisches ${ }^{6}$ Beispiel für das Neben- bzw. Miteinander von römischem Militär und einheimischer Bevölkerung vor der Zeitenwende und weist auf eine wichtige Variante für römische Militärpräsenz in nachcaesarischer Zeit und vor der Etablierung von großen militärischen Einheiten in entsprechenden Basen an der Rheinfront hin. ${ }^{89}$ Ähnliches ist für Vindonissa/Windisch oder Basel festzustellen. Denn auch die Ergebnisse der Ausgrabungen in Windisch-Breite lassen auf die Stationierung autonomer Trupps des römischen Militärs vor Errichtung des Legionslagers schließen. Dabei könnte es sich um kleinere Formationen gehandelt haben, die gegebenenfalls auch den einheimischen Bewohnern an die Seite gestellt wurden, oder auch um Angehörige von Hilfstruppen, wobei diese nicht notwendigerweise ihrer Struktur nach den Auxilien der späteren Zeit geglichen haben müssen, oder auch um gemischte Formationen, mit denen man jedenfalls verstärkt bis in die Frühphase des Principats zu rechnen hat. ${ }^{90}$ Vergleichbar ist diesbezüglich auch die Situation in Basel (Münsterhügel), wo in einem Horizont, der um 30-25 v. Chr. beginnt und vor allem für das 2. Jahrzehnt v. Chr. (Dangstetten-Horizont; Alpenfeldzüge) charakteristisch ist, die Präsenz einer kleinen römischen Garnison an der Seite indigener Bevölkerung unter adliger Führung nachgewiesen wurde. ${ }^{91} \mathrm{Ob}$ hier auch der Limberg b. Sasbach am nördlichen Kaiserstuhl eingereiht werden kann, muss angesichts der nicht eindeutigen Befunde und Datierung offen bleiben. ${ }^{92}$ Möglicherweise war das Mit- oder Nebeneinander von römischem Militär und einheimischen Bewohnern etwa in Oppida bis weit in die augusteische Zeit hinein eine verbreitete Erscheinung und gewissermaßen der (oder ein?), Normalfall‘ in Gallien. Die Forschungen der jüngeren Vergangenheit insbesondere auf französischem Territorium zeigen allerdings, dass eine solide Absicherung der Funktion und Chronologie für die nur wenigen nachgewiesenen römischen Posten oder Lager nach wie vor problematisch ist. ${ }^{93}$ Grundsätzlich bleibt es daher erforderlich, jeden einzelnen Fall hinsichtlich der eigenen Voraussetzungen und Konsequenzen genau zu prüfen.

\footnotetext{
${ }^{86}$ Dio 51,20,5; 51,21, 5 f. - Carrinas feierte wegen seines Sieges einen Triumph. Zur Person s. PIR ${ }^{2}$ C 447.

${ }^{87}$ SCHÖNBERGER 1985, 431 A 31; LÖHR/TRUNK 2008; REDDÉ 2011/2, 69 f.

${ }^{88}$ Grundlegend MetZLER 1995.

${ }^{89}$ MeTZLER 1995, bes. 519-528. S. aber dazu auch REDDÉ 2008/1, 14.

${ }^{90}$ HAGENDORN U.A. 2003, 464-466 mit Abb. 69; ferner zuletzt ReDDÉ 2015, 306 f. mit Hinweis auf Schlussfolgerungen aus dem archäologischen Material, wonach seit dem 2. Jahrzehnt v. Chr. zwar kleinere militärische Abteilungen sowohl im Oppidum als auch am Fuße desselben anwesend waren, ein geschlossenes Legionslager im eigentlichen Sinn aber nicht vor der tiberischen Zeit nachzuweisen ist.

${ }^{91}$ DESCHLER-ERB 2011, 239-247.

92 Dazu etwa WendLING 2005, 97-99. Deutung und Datierung der Befunde sind umstritten. Vgl. dazu schon SCHÖNBERGER 1985, 434 A 46, ferner REDDÉ 2015, 307.

${ }^{93}$ REDDÉ 2011/2, 63. - Einzelheiten ebd. 63-66 mit den Plänen 1-4; ferner REDDÉ 2008/2, bes. 434 mit dem Schluss: „Sans doute quelques découvertes archéologiques récentes ont-elles apporté à notre curiosité des lueurs intéressantes, mais très limitées. À Mirebeau, à Faux-Vésigneul, à Arras-La Corette, à
} 
Eine andere Form des Miteinanders von römischem Militär und ziviler Bevölkerung ist die Beteiligung der Armee an Aufbau und Entwicklung größerer, auch ziviler Siedlungen, wie das Beispiel Waldgirmes an der Lahn im Bereich der Germania magna lehrt, ${ }^{94}$ was aber auch für die Entwicklung von Orten in der Gallia Comata als wahrscheinlich anzunehmen ist. ${ }^{95}$ Zur Vermeidung von Fehlschlüssen gilt es jedoch stets zu bedenken, dass der Nachweis von römischen militaria nicht zwingend die Stationierung von Truppen, insbesondere von Legionären, bezeugt. Ihre sachgerechte Interpretation bedarf jedenfalls der Berücksichtigung des jeweiligen archäologischen und historischen Kontextes. $^{96}$

Wohl eher in die zweite Statthalterschaft des Agrippa fallen die Anlage von Fernstraßen und weitere organisatorische Maßnahmen in Gallien. ${ }^{97}$ Der Straßenbau diente zuvorderst militärischen Zwecken. Eine dieser Routen verband Lugdunum/Lyon mit dem Rhein (Köln) und führte auch durch die Gebiete der Haeduer und Treverer. ${ }^{98}$ Kennzeichnend ist diesbezüglich auch der dendrochronologisch in das Jahr 18/17 v. Chr. zu datierende Bau einer Brücke über die Mosel, wo im Verlauf des folgenden Jahrzehnts das urbane Zentrum der colonia Augusta Treverorum entstand. In der Folgezeit kam es zu Truppenverlagerungen in den Raum des nordöstlichen Gallien, möglicherweise begünstigt durch den Abzug von Truppen aus Hispanien nach Ende der Cantabrerkriege. ${ }^{99}$ Von zentraler Bedeutung war dann aber die Verschiebung der römischen Truppen in ihrem Kernbestand aus dem Inneren Galliens in die Grenzzone am

Melun, à Saintes (inédit) la mise en évidence de véritables postes ou camps militaires romains antérieurs à la période augustéenne permet d'affirmer que l'armée disposait de cantonnements autonomes, hors de tout agglomération indigène. Mais nous ne saurions y connaître des bases occupées durablement ..." Es mag sich bei den umfangreichen Anlagen wie etwa bei Mirebeau und Faux-Vésignol (Marne) auch eher um Sommerlager als um hiberna handeln, aber genaue Zeitstellung und Dauer ggf. bis in die frühaugusteische Zeit sind ungewiss, und es bleibt zu prüfen, ob nicht die römischen Truppen auf verschiedene Oppida verteilt überwinterten, wie Caes. b. Gall. 7,90 zum Jahr 52 v. Chr. vermerkt. In Melun auf der linken Seite der Seine wird auch eine Versorgungsstation mit Speicherbauten für möglich erachtet. In anderen Fällen verweisen die archäologischen Spuren auf kleinere Posten. - Die im Zitat gezogene Schlussfolgerung gilt im strengen Sinn nicht nur für die Zeit vor Etablierung des Principats.

94 BECKER 2003; RASBACH/BECKER 2003; SCHNURBEIN 2003; BECKER/RASBACH 2007; REDDÉ 2008/2, 435 f.; REDDÉ 2009, 178 mit Anm. 16 (weitere Literatur); LEHMANN 2018, 94-104 mit erneutem Verweis auf die lange Zeit verkannte, weil als rhetorisches Schmuckstück erachtete Nachricht bei Dio 56,18,2 f. über die Gründung von $\pi$ ó $\lambda \varepsilon ı \varsigma$ in Germanien vor der Vaus-Katastrophe.

${ }^{95}$ REDDÉ 2008/1, 16-19; REDDÉ 2009, 178-181 zur Frage der Bedeutung des römischen Militärs für die urbane Entwicklung in der Belgica mit Verweis u.a. auf die Situation in den an zentralen Straßenverbindungen gelegenen Atuatuca Tungrorum/Tongern (s. dazu auch VANDERHOEVEN 2013), Ambianum/Amiens oder Bagacum Nerviorum/Bavay, aber auch auf Oberwinterthur. Zur Bedeutung von römischem Militär in der civitas Helvetiorum s. MARTIN-KILCHER 2015, 262-273. Eine planmäßige Beteiligung der römischen Armee bei der Gründung von Städten und stadtähnlichen Siedlungen könnte dann in eine evolutionäre Entwicklung übergegangen sein, die im Wesentlichen von der ansässigen Bevölkerung getragen und bestimmt wurde.

${ }^{96}$ Vgl. bes. PoUX (HG.) 2008 mit Kartierung von militaria in Gallien aus caesarisch-augusteischer Zeit S. 420 in Abb. 73, wieder abgebildet auch bei REDDÉ 2009, 174 Abb. 4 und REDDÉ 2011/2, 68 Abb. 5. Es kann verschiedene Gründe haben, dass derartige Ausrüstungsgegenstände gewollt oder ungewollt in die Hände von Einheimischen gelangten. Wie schon weiter oben (Anm. 78) ausgeführt, ist auch der Nachweis von Terra sigillata an einem Ort kein zwingender Beleg für die Anwesenheit römischen Militärs oder gar eines Lagers. Entsprechend differenziert sind auch die Münzfunde und die Streuung gestempelter Ziegel von Truppen zu bewerten. Vgl. zu den methodischen Problemen der Interpretation besonders REDDÉ 2008/2 und REDDÉ 2009.

${ }^{97}$ Zum Straßenbau s. bes. Strab. 4,6,11 = $208 \mathrm{C}$ und dazu HANEL 2015, 166 mit der Literatur in Anm. 10.

${ }^{98}$ Sie griff auf alte, schon von Caesar genutzte Kommunikationsachsen u.a. entlang der Saône und weiter zum Ozean zurück.

${ }^{99}$ Vgl. dazu Kemmers 2007, 189; GARCÍA-BELlido 2007, 165; HANEL 2015, 169 f., wo Truppen aus Hispanien aber erst mit den Feldzügen des Drusus in Verbindung gebracht werden. 
Rhein nach der clades Lolliana $16 \mathrm{v}$. Chr., ${ }^{100}$ als sich offenbar auf den wachsenden römischen Druck hin Sugambri, Usipites und Tencteri unter ihrem König Maelo erhoben hatten. Sie hatten 20 Centurionen gekreuzigt, die möglicherweise mit der Eintreibung von Tributen oder mit Rekrutierungsmaßnahmen befasst waren. Einer zur Hilfe herbeieilenden Legion unter M. Lollius bereiteten sie zunächst eine schwere Schlappe, welche zum Verlust des Adlers einer 5. Legion führte, die dann aber wohl rasch wettgemacht werden konnte. ${ }^{101}$ Dies eröffnete mit den Feldzügen des Drusus ab $12 \mathrm{v}$. Chr., die tief in die Germania magna hinein bis zur Elbe reichten, eine neue Phase der militärischen und politischen Beziehungen zwischen Rom und den Völkerschaften an diesem Grenzabschnitt des Imperiums. ${ }^{102}$ Als militärische Stationen am nördlichen Abschnitt des Rheins noch vor den Drusus-Feldzügen werden Noviomagus/Nijmegen (Hunerberg) ${ }^{103}$ und Novaesium/Neuss (Gnadenthal) ${ }^{104}$ angenommen, Asciburgium/ Moers Asberg wird für möglich erachtet. ${ }^{105}$

Es kann nach Verschiebung der Truppen an die Rheinfront aber nicht die Rede davon sein, dass diese in ihrer ganzen Länge und unter Berücksichtigung sowohl des Hinterlandes in Gallien als auch der Front gegenüber Germanien einheitlichen Charakter aufwies. Die bekannte Schwerpunktverlagerung der militärischen Aktionen Roms vom Süden in den Norden unter Augustus hatte auch Folgen für die militärischen Dispositionen entlang des Stromes. Die Lage in den Grenzgebieten vom Hoch- und Oberrhein bis zum südlichen Mittelrhein war seit Übernahme des Principats durch Augustus durchweg friedlich, die Alpenfeldzüge dienten der Vorfeldsicherung Italiens. Anders gelagert waren dagegen die Verhältnisse am Niederrhein und im nördlichen Teil des Mittelrheins, wobei die Truppenkonzentration in und um Mainz gleichermaßen der Sicherung wie der Nutzung von Einfallswegen in das Innere der Germania magna diente. Rom reagierte auf die unterschiedliche Ausgangslage, und dies wirkte sich auch auf die Truppengeschichte aus. Während Mogontiacum/Mainz ${ }^{106}$, Ara Ubiorum/

\footnotetext{
${ }^{100}$ Diese Datierung wird heute im Allgemeinen derjenigen in das Jahr 17 v. Chr. vorgezogen.

${ }^{101}$ Zusammenstellung der Quellen erneut bei HANEL 2015, 166-168 in den Anmerkungen. Sueton (Aug. 23,1) bewertet die Niederlage als Angelegenheit magis infamiae quam detrimenti.

102 Aus der kaum überschaubaren Fülle an zusammenfassenden und auch speziellen Studien zur Geschichte der friedlichen Kontakte und feindlichen Begegnungen zwischen Rom und den Völkerschaften in Gallien und Germanien in der Zeit nach Caesar bis zu Augustus sei etwa auf die eingehende quellenkritische Untersuchung von WOLTERS 1990, 134-198 mit der Bibliographie auf S. 285-300 verwiesen. Vgl. ferner CHRIST 1977 sowie die verschiedenen detaillierten Studien von Timpe, die bequem bei TIMPE 2006 gesammelt vorliegen. Zu ergänzen sind diese u.a. durch seine Ausführungen im RGA ${ }^{2}$-Artikel zu den Germanen 1998. Die Grundansichten von WELLS 1972 zur augusteischen Germanienpolitik sind vielfach jenseits der berechtigten Anerkennung für die Zusammenfassung der seinerzeit verfügbaren archäologischen Erkenntnisse kritisch gewürdigt worden. Zu neueren Befunden und Erkenntnissen zu den römisch-germanischen Auseinandersetzungen s. zuletzt die Übersicht von LEHMANN 2018 mit aktueller Literaturauswahl. Ein grundlegender Ausgangspunkt für die Frage der Truppenlager zwischen Nordsee und Inn ist nach wie vor SCHÖNBERGER 1985.

103 HAALEBOS 2002, 405 f.; HANEL 2015, 169-171. - Bei der Größe von 42 ha könnte das Lager zwei Legionen beherbergt haben. Für möglich erachtet wird die früheste Anlage sogar zur Zeit der zweiten Statthalterschaft des Agrippa, also um 19 v. Chr., vgl. KEMMERs 2007, 189-191 und KEMMERS 2008. Die frühe Militäranlage auf dem benachbarten Kops Plateau in Nijmegen datiert wohl in die Zeit der Drusus-Feldzüge.

${ }^{104}$ HANEL 2002; GeChTER 2003, 147-149; vgl. HANEL 2015, $170 \mathrm{f}$.

${ }^{105}$ HANEL 2015, 171.

${ }^{106}$ Von Mainz aus marschierten zwei Legionen nach der Niederlage des Varus im Jahr 9 an den Niederrhein (Vell. 2,120,1). Der Zeitpunkt ihrer gemeinsamen Stationierung ist allerdings ebenso fraglich wie die jeweiligen Lagerplätze. Militärische Besatzung - in welcher Form und Größenordnung auch immer - ist bereits ab der Drusus-Zeit vorauszusetzen, vgl. SCHÖNBERGER 1985, 334 mit 341 f. und 432 A 33 34.
} 
Köln ${ }^{107}$ und Vetera (I)/b. Xanten ${ }^{108}$ als Legionslager für zwei Legionen bereits seit der Zeit des Augustus Bestand hatten, ${ }^{109}$ ist für die Legionslager in Vindonissa/Windisch und Argentorate/Straßburg festzuhalten, dass deren Anlage und Besetzung durch jeweils eine Legion entgegen früherer Ansicht kaum vor der Regierungszeit des Tiberius erfolgten, jedenfalls gibt es keine diesbezüglich eindeutigen Zeugnisse. ${ }^{110}$

Herbert Nesselhauf hat mit Recht die Mitteilung des Florus $(2,30)$ über eine Kette von mehr als 50 Kastellen, die der ältere Drusus entlang des Rheins angelegt haben soll, als rhetorisch aufgeputzte Sensationsmeldung entlarvt, andererseits jedoch wohl zu einseitig die Hilfstruppen in iulisch-claudischer Zeit eng bei den Legionen stationiert sein lassen. ${ }^{111}$ Dem widerspricht nicht die Zuordnung zu den verschiedenen Heeresverbänden. Zwar waren Hilfstruppen bis in die Frühphase des Principats nicht selten mit den Legionen zusammen in Lagern stationiert, ${ }^{112}$ dann aber erforderte vor allem die Anlage einer Kastell- und Postenreihe entlang des Rheins in Folge einer veränderten Strategie auch ein Auseinanderziehen der Einheiten. Dies gilt vor allem für eine ganze Reihe militärischer Anlagen, die erst in Folge der tiberischen Sicherungspolitik nach Rückberufung des Germanicus angelegt wurden. ${ }^{113}$ Hierzu zählt am Hochbzw. Oberrhein neben Vindonissa und Argentorate insbesondere das hinsichtlich seiner Größe und Anlage untypische früheste Lager (B) in Oedenburg/Argentovaria (?) südlich von Straßburg, das zwischen 15 und 20 errichtet wurde und um 30 durch ein zweites Lager (A) überbaut wurde, bis auch dieses 70/71 aufgegeben wurde. ${ }^{114} \mathrm{Zu}$ erwähnen

${ }^{107}$ Das Zweilegionenlager „,apud Aram Ubiorum“ wurde zwischen 9 und 14 errichtet. Möglicherweise weisen Spuren auf ein älteres Lager, vgl. Schönberger 1985, 429 A 15. Das Kastell für die classis (Augusta) Germanica in Köln-Alteburg wurde anfangs der 30er Jahre gegründet. Vgl. zur frühen Geschichte des römischen Köln ECK 2004.

${ }^{108} \mathrm{Im}$ Jahr 14 lagen in Vetera jedenfalls zwei Legionen, aber bereits ab 13/12 v. Chr. dürfte am Ort ein Lager bestanden haben, vgl. SCHÖNBERGER 1985, 427 A 8. Spuren des Doppellegionslagers stammen aus tiberisch-claudischer Zeit.

${ }^{109}$ Auf Einzelheiten wie etwa den jeweils frühesten Zeitpunkt der Errichtung dieser Lager und die Vorgeschichte der militärischen Besetzung dieses Grenzabschnittes, aber auch auf die Geschichte der verschiedenen Legionen kann und braucht an dieser Stelle nicht näher eingegangen zu werden. Es genügt, auf RITTERLING 1924/25, passim zu den einzelnen Legionen und auf SCHÖNBERGER 1985, bes. 326-358 mit dem Überblick über die militärischen Anlagen in iulisch-claudischer Zeit sowie insbesondere auf den Katalog A ebd. 425-438 (mit entsprechender Kartierung) hinzuweisen.

${ }^{110} \mathrm{Zu}$ Vindonissa bes. HAGENDORN U.A. 2003. - Zu Argentorate/Straßburg s. BAUdOUX U.A. 2002, SCHNITZLER/KUHNLE (HG.) 2010 und zuletzt REDDÉ 2015, 300-305 mit Diskussion der aktuellen Grabungsergebnisse. Nach derzeitigem Wissensstand deuten die ältesten Spuren von typischen militärischen Strukturen frühestens in die Zeit nach dem Ende von Haltern bzw. in die frühtiberische Zeit.

111 NeSSELHAUF 1960, 151-160. - Eine veritable Kastellkette im Elsass entlang des Rheinverlaufs mit Basel, Kembs, Kunheim-Biesheim, Straßburg und Forstfeld hatte etwa HATT 1978, 32 postuliert, s. dazu aber schon REDDÉ 2005 und zuletzt REDDÉ 2015, 299. Hinweise auf militärische Präsenz Roms liegen vor allem für Cambete/Kembs (Haut-Rhin) vor. Der Lage nach war der Ort als Endpunkt der Straße von Mandeure an den Rhein zugleich ein günstiger Platz für einen Rheinübergang. Hier wurden auch militärische Objekte gefunden und zudem der Rest eines römischen Reitergrabsteins. Aber Typus einer möglichen militärischen Anlage und genaue Zeitstellung sind nach wie vor unbekannt. Vgl. zu den militaria FORT 2003 und zu dem Reitergrabstein WIEGELS 2007. Zu den Deutungsmöglichkeiten s. schon REDDÉ 2009, 176 f. - Zu Oedenburg s. im Folgenden.

112 Dabei ist aber nicht immer davon auszugehen, dass dies stets die Einheiten in voller Sollstärke umfasste.

${ }^{113}$ Grundsätzlich eröffnet die Frage nach Identifizierung, Besatzung und Dauer der Truppenlager ein eigenes Forschungsfeld, das der periodischen Überprüfung und Aktualisierung der Erkenntnisse bedarf und der diesbezüglichen Spezialforschung vorbehalten bleiben muss. Auf ein up-date muss an dieser Stelle verzichtet werden.

114 REDDÉ (HG.) 2009; REDDÉ 2015, 305 f. mit Überlegungen zur ersten Besetzung des Lagers (Ala? / gemischte Truppe aus Legionären und Hilfstruppen?). - Vgl. auch die Karte mit Erläuterungen und weiterer Literatur von REDDÉ 2013. 
sind aber auch die unter Tiberius erbauten Lager bei Augst, Zurzach und in Konstanz als Stationierungsorte für Begleittruppen der Legion in Vindonissa. ${ }^{115}$ Offene Fragen ergeben sich für die bis Mainz verlaufende Rheinlinie und den Zeitpunkt der dort an der Straße von Basel nach Mainz etablierten Anlagen wie Speyer und Worms. ${ }^{116} \mathrm{Im}$ niedergermanischen Grenzbereich wurde offenbar im Zuge und nach den Drususfeldzügen eine Kette militärischer Anlagen entlang des linken Rheinufers angelegt. ${ }^{117}$ Für Einzelheiten zu den frühen Truppenlagern sei hier lediglich pauschal auf die zusammenfassenden Ergebnisse von Hans Schönberger aus dem Jahr 1985 verwiesen, die eine annähernd gleiche Anzahl an Gründungen von Militärstationen in augusteischer wie in tiberischer Zeit bezeugen. ${ }^{118}$ Die Errichtung dauerhafter römischer Militärstützpunkte führte aber zu verschiedenen lokalen und regionalen Entwicklungen, wobei weitere Faktoren zu berücksichtigen wären. Beispielhaft sei auf das Helvetiergebiet und angrenzende anschließende Zonen verwiesen. Während etwa Urbanisierung und ,Romanisierung/Romanisation“ im Helvetiergebiet rasch einsetzten und bemerkenswerte Verbreitung fanden, ${ }^{119}$ überdauerten im Oberrheingebiet beiderseits des Stromes prähistorische Strukturen in der Ebene bis in die tiberische Zeit hinein und noch darüber hinaus. ${ }^{120}$

Die Feststellung, dass im Jahr 23 die stärkste Heeresmacht des Imperiums am Rhein stand, wird durch die Übersicht des Tacitus über die Zusammensetzung der Heere in anderen Grenzbereichen deutlich vor Augen geführt. Nach der clades Variana $9 \mathrm{n}$. Chr. war das Rheinheer von fünf oder sechs auf acht Legionen aufgestockt worden, die in zwei Heeresbereiche aufgeteilt wurden, ${ }^{121}$ aber zunächst unter dem einheitlichen Kommando des Tiberius, dann des Germanicus standen. Nach dessen Abberufung blieb das Heer im Zuge einer veränderten Strategie auf zwei eigenständige Verbände von je vier Legionen untergliedert, den exercitus Germanicus superior mit den Standorten Vindonissa, Argentorate und Mogontiacum (im Doppellegionslager) und den exercitus

\footnotetext{
115 Zum Kastell bei Augst, welches anscheinend etwa zeitgleich mit dem Legionslager in Vindonissa errichtet wurde und bis um die Mitte des 1. Jahrhunderts besetzt war, s. DESCHLER-ERB U.A. 1991; zu Zurzach s. HÄNGGI 1986; zu Konstanz (Gründung um 20) MAYER-RAPPERT 2003. Vgl. auch HARTMANN/SPEIDEL 1991, bes. 3 f.; SPEIDEL 1996, 173-175 (Zusammenfassung); FELLMANN 1992, 30-40 (Übersicht) mit der Kartierung S. 31, Abb. 15: période tibérienne und 39 Abb. 23: époque claudienne.

116 Zusammenfassende Übersicht s. BERNHARD 1986. - Zu Noviomagus Nemetum/Speyer: SCHÖNBERGER 1985, 433 A 43; BERNHARD 1990/2, 557-561. Zu Borbetomagus/Worms: SCHÖNBERGER 1985, 433 Nr. 42; GRÜNEWALD 1990, bes. 673; GRÜNEWALD 2012, 32-41. Vgl. auch REDDÉ 2015, 309. - Das frührömische Hilfstruppenlager (für eine Ala?) in Ludwigshafen-Rheingönheim dürfte wohl erst um 43 angelegt worden sein, s. BERNHARD 1990/1, 455-457 mit dem Plan auf S. 456.

117 Übersicht bei GECHTER 1979.

118 SCHÖNBERGER 1985, 331-334 mit Diskussion des Forschungsstandes zu den einzelnen militärischen Anlagen A 425-438 im Katalog mit Karte A.

119 S. etwa MARTIN-KILCHER 2015.

${ }^{120}$ Allgemein zur Situation an Mittel- und Oberrhein vor der Zeitenwende Fichtl 2000. - Zum Elsass s. FLOTTÉ U.A. 2006; ZEHNER 2010; REDDÉ 2015, 307 f.; NÜSSLEIN U.A. 2017. Zu Brocomagus/Brumath, dem Vorort der Triboker, können bislang nur unter Vorbehalt Aussagen getroffen werden. Danach stammen die ersten Siedlungsspuren aus der Zeit zwischen dem Ende des 1. Jh. v. Chr. und dem Beginn des 1. Jh. n. Chr. Der städtische Charakter ist ab 30/40 deutlich erkennbar, als ein Wohnviertel und öffentliche Thermen gebaut wurden, vgl. FLOTTÉ 2016. - Zur östlichen Oberrheinebene s. bes. BLÖCK 2016. Hier dokumentiert die Villa von Heitersheim ab etwa 30 den mediterranen Einfluss. Ähnliches gilt für die Villa von Laufenburg am Hochrhein. Es hat aber nicht den Anschein, dass Angehörige der Armee etwa nach ihrer Entlassung für den Zivilisationsschub verantwortlich waren.

${ }^{121}$ Nach Tac. ann. 1,31,2 bestanden sie jedenfalls im Jahr 14. Die Verteilung der Legionen auf die beiden Heeresverbände s. Tac. ann. 1,37. Wo genau diese Truppen bzw. andere Legionen an der Rheinfront in augusteischer Zeit vor dem Jahr 9 lagerten, lässt sich nicht in allen Fällen sicher erschließen.
} 
Germanicus inferior mit den Standorten Ara Ubiorum und Vetera (jeweils Doppellegionslager). ${ }^{122}$ Ein eigenes Problem stellt die Identifizierung und Dislokation der nicht wenigen Auxiliarformationen dar, wobei viele Fragen angesichts der besonders stark vom Zufall geprägten epigraphischen Überlieferung notgedrungen ungeklärt bleiben müssen. Hinzu kommt, dass diese Quellen nicht immer mit der gewünschten Genauigkeit zeitlich einzuordnen sind. ${ }^{123}$

Die Konzentration einer großen Anzahl von Truppen mit entsprechend zahlreichem Dienst- und Begleitpersonal ${ }^{124}$ hatte jedoch als gravierendes Problem deren Versorgung vor allem mit Grundnahrungsmitteln zur Folge. ${ }^{125}$ In der Frontzone am Rhein fehlten zunächst weitgehend die Voraussetzungen für eine entsprechend erforderliche Mehrproduktion insbesondere an Getreide durch die ländliche Bevölkerung. ${ }^{126}$ Die diesbezügliche Entwicklung des ländlichen Raumes vollzog sich nur langsam, landwirtschaftliche Großgüter entstanden erst mit deutlich zeitlichem Abstand zur Errichtung der Lagerkette. Zudem musste den unterschiedlichen naturräumlichen Bedingungen und Lebensgewohnheiten der traditionell ansässigen Bevölkerung, die weitgehend eine Subsistenzwirtschaft pflegte, Rechnung getragen werden. Ihre Wirtschaftsweise war in weiten Gebieten geprägt durch Dominanz der Viehhaltung gegenüber dem Ackerbau. Dies hatte nicht zuletzt auch Konsequenzen für die unentbehrliche Versorgung der vergleichsweise dichtbevölkerten Militärzonen am Rhein mit ihren besonderen Bedürfnissen. ${ }^{127}$ Dementsprechend ist es erforderlich, die regionalen oder auch lo-

122 Vindonissa: leg. XIII Gemina; Argentorate: leg. II Augusta; Mogontiacum: leg. XIV Gemina und XVI (Gallica). - Ara Ubiorum: leg. I (Germanica) und XX Valeria Victrix; Vetera: leg. V Alaudae und XXI Rapax. Diese Verteilung hatte bis gegen Ende der Regierung des Tiberius Bestand.

${ }^{123} \mathrm{Zu}$ den Auxiliarverbänden liefert STEIN (/RITTERLING) 1932 nach wie vor eine wichtige Basis, die aber auf Grund neuer Funde und Erkenntnisse sowie einer Reihe von Spezialstudien ergänzungsbedürftig ist. Nicht immer zuverlässig sind die übergreifenden Zusammenstellungen und Erörterungen bei SPAUL 1994 zu den Alen und SPAUL 2000 zu den Kohorten. Angesichts der Fülle und Heterogenität des Materials sollten aber die Schwierigkeiten bei der Umsetzung der beiden ambitionierten Projekte nicht verkannt werden. Zum niedergermanischen Heer hat ALFÖLDY 1968 die einschlägige Vorarbeit geleistet, zum obergermanischen Heer liegen ebenfalls wichtige Studien der jüngeren Vergangenheit vor, worauf an anderer Stelle näher eingegangen werden soll.

${ }^{124}$ Auch wenn jede Zahlenkalkulation mit Unsicherheiten befrachtet ist, muss man wohl mit mehr als 50.000 Soldaten in den am Rhein in tiberischer Zeit stationierten Legionen und Hilfstruppen einschließlich Begleitpersonal rechnen.

125 Grundlegend zur Ernährung im römischen Heer DAVIES 1971; BREEZE 1993. - Zu den Truppen an den Grenzen WIERSCHOWSKI 1984; WHITTAKER 1994; REMESAL RODRÍGUEZ 1997 sowie verschiedene Beiträge in ERDKAMP (HG.) 2002. Speziell zur Lage bei den rheinischen Grenztruppen seit Tiberius REDDÉ 2011/1 mit der weiterführenden Literatur. - Seit einigen Jahren haben in der Forschung Karpologie und Archäozoologie an Bedeutung gewonnen und zu wichtigen Erkenntnissen zur Versorgung der Truppen beigetragen. Dies gilt sowohl für die Ernährungsgewohnheiten der Truppen, soweit sie jedenfalls noch vor allem in Italien rekrutiert wurden, als auch der einheimischen Bevölkerung etwa Galliens, die Unterschiede aufweisen.

${ }^{126}$ Vgl. REDDÉ 2011/1, bes. 490-492 mit Hinweisen zu den Forschungspositionen und zum Verhältnis zwischen römischem Militär im Grenzgebiet und der Entstehung einer Gutswirtschaft in großem Stil. Nach traditioneller Sicht waren Veteranen und ihre Nachkommen ein entscheidender Faktor für die Entwicklung der ökonomischen Infrastruktur, sei es als Eigentümer von Gutshöfen oder als Kaufleute und Händler. Enge Beziehungen zwischen ehemaligen und aktiven Soldaten führten dazu, dass Erstere sich verstärkt im Umfeld ihres ehemaligen Stationierungsortes niederließen und gleichsam eine population militaire bildeten (REDDÉ 2011/1, 492 Anm. 11 entsprechend einer Einlassung von P. Le Roux). Zu berücksichtigen sind jedoch Zeitfaktor (Entwicklungsstufen) und die unterschiedlichen naturgegebenen Voraussetzungen für die landwirtschaftliche Produktion.

${ }^{127}$ Die Forschung hat sich in den letzten Jahren verstärkt und mit Gewinn den ländlichen Räumen und den dortigen Entwicklungsprozessen zugewandt, vgl. für Gallien das Projekt, Gallia Rustica‘ mit Beiträgen in einem ersten, von M. Reddé 2017 herausgegebenen gewichtigen Band Gallia Rustica I. Zu den 
kalen Voraussetzungen einschließlich des sozialen und kulturellen Umfeldes zu beachten. ${ }^{128}$ Zwar sind vorschnelle Generalisierungen problematisch, dennoch fehlt es nicht an Hinweisen, dass insbesondere in der Frühphase der Anlagen von Truppenstationen mit einer vergleichsweise hohen Konzentration an Einheiten ab Tiberius die Armee weitgehend auf die Versorgung auch mit Getreide von Produktionsstätten außerhalb des unmittelbaren Umfeldes angewiesen war, und das war in erster Linie das angrenzende Gebiet der Belgica. ${ }^{129}$ Anlagen von Villen wie diejenige von Heitersheim am Oberrhein, die wohl von Siedlern aus Gallien und nicht von ehemaligen Angehörigen des Heeres erbaut und bewirtschaftet wurde, blieben für längere Zeit die Ausnahme in einem im Übrigen durch kleinere Gutshöfen charakterisierten Umfeld. Jedenfalls gibt es keine zureichenden Belege dafür, dass das römische Militär selber als Institution mit eigenem Personal im Dienst oder nach der Entlassung in der Frühzeit des Principats am Rhein umfassend Ackerbau und Viehzucht betrieben hätte, um die entsprechenden Bedürfnisse der Truppen zu befriedigen. Die Diskussion um die sogenannten ,Militärterritorien' bzw. prata legionum hat nicht zu einem entsprechenden Ergebnis geführt. ${ }^{130}$ Demnach zählte die Beschaffung der notwendigen Grundnahrungsmittel zur Versorgung der Truppen über längere Zeit hinweg aus einem Umfeld mit großem Radius um die Lager zu den wichtigsten Erfordernissen der Logistik des Heeres. ${ }^{131}$ Dies gilt unabhängig von speziellen Massengütern wie Öl oder Wein, die gegebenenfalls über den Fernhandel mit und ohne staatliche Aufsicht herbeigeschafft werden mussten. ${ }^{132}$ In eine andere Kategorie fallen selbstverständlich Luxusgüter der verschiedensten Art, welche nachweislich über den (Fern-)Handel auch die Militärstationen erreichten.

Entwicklungen in verschiedenen Zonen an Rhein und Donau und den Villenlandschaften s. REDDÉ 2011/1, bes. 495-503 mit der speziellen Forschungsliteratur. Für das südliche Oberrheingebiet östlich des Flussverlaufs sei noch auf die Untersuchung von BLÖCK 2016 auf archäologischer Grundlage hingewiesen. Zum Elsass vgl. hier Anm. 120 mit der Literatur.

${ }^{128}$ Vgl. dazu REDDÉ 2011/1, 504 mit der (vorläufigen) Schlussfolgerung: ,il n'existe pas de modèle global pour comprendre la logistique militaire romaine, mais uniquement des modèles locaux, variables en fonction du potential agricole et du niveau de développement de l'agriculture antérieur à la conquête ... il est essentiel d'intégrer dans notre raisonnement la dimension chronologique ... Il conviendrait d'y ajouter une phase intermédiaire, entre la conquête et la consolidation du limes."

${ }^{129} \mathrm{Vgl}$. REDDÉ 2011/1, 489: „Il apparait que les conditions écologiques et la faiblesse de l'agriculture indigène n'étaient pas capables de subvenir aux besoins militaires. De ce fait, la nourriture des troupes, très nombreuse à cette époque, a reposé sur des importations de Gaule Belgique, dont les campagnes ont été soumises à des forts, prélèvements, générateurs de révoltes au I ${ }^{\text {er }}$ siècle de notre ére, avant que la situation économique ne s'inverse à partir de l'époque flavienne."

${ }^{130} \mathrm{Zu}$ dem viel behandelten Problem der ,Militärterritorien“ bzw. prata legionum s. nach SCHULTEN 1894 insbesondere MÓCSY/BARKÓCSY 1954; SANDER 1958, 193-198; MÓCSY 1967; RÜGER 1968, 50-75 mit der Karte auf S. 37; VitTinghoff 1974; Wiegels 1989; BÉRARd 1992 und RedDÉ 2011/1, 492-494. Ausgangspunkt der Diskussion waren nicht zuletzt eine Inschrift aus Aquincum/Budapest mit Erwähnung eines territorium legionis (CIL III 10489) und nicht wenige Grenzsteine aus Hispanien, welche prata leg(ionis) IIII et agrum Iuliobrig(ensium) voneinander schieden (e.g. CIL II 2916 - über 20 derartige Steine sind bekannt; dazu eine Inschrift aus Burnum (Dalmatia) [ILS 5968]). Ein Versuch, derartige Territorien in ihren Grenzen annähernd zu erfassen, beruhte auf der Streuung gestempelter Ziegel des Militärs, vgl. etwa GONZENBACH 1963 zu den gestempelten Ziegeln im Umkreis des Legionslagers von Vindonissa, die aber weniger ein rechtlich dem Militär zugeordnetes Territorium rekonstruiert als ein Interessengebiet. CONRAD 2004, 13 ist der Ansicht, dass jedem Legionslager und Kastell ein Territorium zuzuordnen sei. Gegen ein juristisch definiertes Territorium s. aber vor allem VITTINGHOFF 1974.

${ }^{131}$ REDDÉ 2011/1, 492-494.

132 Zur Versorgung der Truppen in Germanien mit Öl vor allem aus der hispanischen Provinz Baetica und hier vor allem den Produktionszentren entlang des Baetis/Guadalquivir und die diesbezüglichen Versorgungsrouten s. etwa REMESAL RODRÍGUEZ 1997. Dies trifft für die gesamte Principatszeit zu, wie die entsprechend markierten Amphoren beweisen. 
Die von der Obmacht Rom gewünschte und auch eingeforderte Gewährleistung dieser Unterhaltsleistung durch die Provinzbevölkerung der Gallia Comata war für Rom also praktisch unverzichtbar und auf politischer Ebene offenbar zumindest zum Teil auch Ersatz für eine Befreiung von direkten militärischen Leistungen durch Bereitstellung von einheimischen Truppenverbänden in größerem Umfang. In normalen Zeiten mochte die Versorgung der Rheintruppen mit den notwendigen Gütern vor allem aus dem Bereich der Belgica ${ }^{133}$ bei entsprechenden Voraussetzungen für die Produktion einigermaßen funktionieren, in Krisenjahren allerdings konnte dies auch zu generellen Versorgungsproblemen führen. Dann traf die Einforderung von Tributen und Naturalabgaben sicherlich besonders die einfache Bevölkerung, auf welche die Lasten durch die aristokratische Führungsschicht im Zweifelsfall abgewälzt wurden. Die begleitenden Umstände zum Trevereraufstand 23 deuten auf entsprechende Zusammenhänge hin, zumal die Heeresmacht Rom weder dazu bereit noch letztlich in der Lage war, auf eingegangene Verpflichtungen der ansässigen Civitates zu verzichten. ${ }^{134}$ Auslöser dieses Aufstandes waren nach den Worten des Tacitus (ann. 3,40,3) nicht etwa aktuell neu eingeforderte Abgaben, sondern insbesondere die ununterbrochen fortgesetzte Einforderung von Tributen (continuatio tributorum) auch nach Aufgabe der Kriegszüge nach Germanien. Zusätzlich erschwerend für die betroffene Bevölkerung kam anscheinend eine länger anhaltende wirtschaftliche Depression hinzu, für die es zumindest einige Anzeichen gibt. ${ }^{135}$ Aber eine Verarmung der Oberschicht in großem Stil ist nicht auszumachen. Dass die Frontstellung der Rheintruppen auch gegen Gallien (Gallia Comata) gerichtet war, dürfte demnach ihren wesentlichen Grund in der Absicherung der Versorgung und Friedenssicherung in Bezug auf diesen Raum haben.

\footnotetext{
${ }^{133} \mathrm{Zu}$ Getreidelieferungen an Caesars Truppen im Gallischen Krieg s. unter anderem oben Anm. 37 und 39. - Aufschlussreiche Informationen im Hinblick auf die Versorgung des Militärs mit täglichen Gebrauchs- und Verbrauchsgütern, aber auch mit Luxusgütern wie Gewürzen, liefern die Tafeln von Vindolanda am Stanegate im Norden Britanniens. Sie betreffen in der auswertenden Zusammenstellung von BOWMAN 1994, 60-73 für einen begrenzten Zeitraum von etwas mehr als einem Dezennium um 100 vor allem den Alltag im praetorium eines Hilfstruppenkastells, im vorliegenden Fall der cohors $I X$ Batavorum. Insgesamt werden über 50 Produkte, die z. T. von weit her (u.a. aus Gallien) herangeschafft werden mussten, genannt. - Zu den Schreibtafeln von Vindonissa s. SPEIDEL 1996, bes. 72 f., der gestützt vor allem auf die Erwähnung einer villa in Taf. Nr. 46 die Versorgung durch umliegende Gutshöfe hervorhebt, jedoch ist zumindest offen, ob der in dieser Tafel dokumentierte Besuch im Lager mit der Güterversorgung in Verbindung steht. Weitere Informationen zu den wirtschaftlichen Verhältnissen in den Grenzbereichen liefern Papyri oder die zunehmend zahlreicher geborgenen Ostraka aus Ägypten.

${ }^{134}$ Aufschlussreich ist diesbezüglich die Rede des Petilius Cerialis in einer Heeresversammlung (contio) gegenüber Treverern und Lingonen im Jahr 70, in welcher er die selbstlose Friedenssicherung Roms für Gallien insbesondere gegenüber den aggressiven Germanen und die Einführung einer Rechtsordnung (ius) als Gewähr für den inneren Frieden hervorhob (Tac. hist. 4, 73 f.). Sein Argument, gleichsam als Climax formuliert, lautet: „Es kann nämlich keine Ruhe unter den Völkern bestehen ohne Waffengewalt, Waffengewalt nicht ohne Sold, Sold nicht ohne Tribute“ (hist. 4,74,1). - S. auch das Urteil des Flavius Iosephus b. Iud. 2, 371-373 (oben Anm. 3).

${ }^{135}$ REDDÉ 2011/1, 504 f. mit Anm. 43 (Literatur).
} 


\section{Siglen:}

$\mathrm{AE}=\mathrm{L}$ 'Année Épigraphique

ANRW $=$ Aufstieg und Niedergang der römischen Welt

$\mathrm{CIL}=$ Corpus Inscriptionum Latinarum

$\mathrm{HZ}=$ Historische Zeitschrift

IIt $=$ Inscriptiones Italiae

ILS = Inscriptiones Latinae Selectae

$\mathrm{PIR}^{2}=$ Prosopographia Imperii Romani

$\mathrm{RE}=$ Realencyklopädie der Klassischen Altertumswissenschaften

REA $=$ Revue des Études Anciennes

RGA $=$ Reallexikon der Germanischen Altertumskunde

\section{Literatur:}

ALFÖLDY 1965 = G. Alföldy, La politique provinciale de Tibère. Latomus 24, 1965, 824-844.

ALFÖLDY 1968 = G. Alföldy, Die Hilfstruppen der römischen Provinz Germania Inferior. Epigr. Stud. 6 (Düsseldorf 1968).

BAudouX U.A. 2002 = J. Baudoux u.a., Strasbourg. Carte Arch. de la Gaule (CAG) 67/2 (Paris 2002).

BECKER 2003 = A. Becker, Lahnau-Waldgirmes. Eine augusteische Stadtgründung in Hessen. Historia 52, 2003, 337-350.

BECKER/RASBACH 2007 = A. Becker/G. Rasbach, ,Städte in Germanien“. Der Fundplatz Waldgirmes, in: R. Wiegels (Hg.), Die Varusschlacht. Wendepunkt der Geschichte? (Stuttgart 2007) 102-116.

BÉRARD $1992=$ F. Bérard, Territorium legionis. Camps militaires et agglomérations civiles aux premiers siècles de l'Empire. Cahiers Glotz 3, 1992, 75-105.

BERNHARD $1986=\mathrm{H}$. Bernhard, Militärstationen und frührömische Besiedlung in augusteisch-tiberischer Zeit am nördlichen Oberrhein, in: Studien zu den Militärgrenzen Roms III.13. Int. Limeskongr. Aalen1983. Forsch. u. Ber. Bad.-Württ. (Stuttgart 1986) 105-121.

BERNHARD 1990/1 = H. Bernhard, Ludwigshafen-Rheingönheim, in: Cüppers (Hg.) $1990455-457$.

BERnHARD 1990/2 = H. Bernhard, Speyer, in: Cüppers (Hg.) 1990 557-567.

BESSONE 1978 = L. Bessone, La sollevazione gallica del 21 D. C. - Floro e Sacroviro: proposta per una interpretazione. N(umismatica e) A(ntichità) C(lassiche) 7, 1978, 143-162.

BLÖCK $2016=$ L. Blöck, Die römerzeitliche Besiedlung im rechten südlichen Oberrheingebiet. Forsch. u. Ber. zur Arch. Baden-Württemberg 1 (Esslingen 2016). 
BOWMAN $1994=$ A. K. Bowman, Life and Letters on the Roman Frontier - Vindolanda and its People (London $1994=$ Ndr. 2002).

BREEZE 1993 = D. Breeze, Demand and Supply on the Northern Frontier. Mavors 10, 1993, 526-552.

BRUNT $1961=$ P. A. Brunt, Charges of Provincial Maladministrate lunder the Early Principate. Historia 10, 1961, 189-227.

BÜCHSENSCHÜTZ 2004 = O. Büchsenschütz, Les Celtes et la formation de l'Empire romain. Annales Histoires, Sciences sociales 59, 2004, 337-361.

BURNAND 2005/10 = Y. Burnand, Primores Galliarum. Sénateurs et chevaliers romains originaires de Gaule de la fin de la République au IIIe siècle. Coll. Latomus, 4 Bde. (Brüssel 2005-2010).

Christ $1977=$ K. Christ, Zur augusteischen Germanienpolitik. Chiron 7, 1977, 149205.

Christopherson $1968=$ A. J. Christopherson, The Provincial Assembly of the Three Gauls in the Julian-claudian Period. Historia 17, 1968, 351-366.

CONRAD $2004=$ S. Conrad, Die Grabstelen aus Moesia inferior (Leipzig 2004).

CÜPPERS (HG.) $1990=$ H. Cüppers (Hg.), Die Römer in Rheinland-Pfalz (Stuttgart 1990).

DAVIES 1971 = R. Davies, The Roman Military Diet. Britannia 2, 1971, 122-142.

DEININGER 1965 = J. Deininger, Die Provinziallandtage der römischen Kaiserzeit von Augustus bis zum Ende des 3. Jahrhunderts n. Chr. Vestigia 6 (München 1965).

Demougin 1992 = S. Demougin, Prosopographie des chevaliers romains julio-claudiens. Coll. EFR 153 (Rome 1992).

DESCHLER-ERB 2011 = E. Deschler-Erb, Der Basler Münsterhügel am Übergang von spätkeltischer zu römischer Zeit. Ein Beispiel für die Romanisierung im Nordosten Galliens. Materialh. Arch. Basel (Basel 2011).

DeSCHLER-ERB U.A. 1991 = E. Deschler-Erb u.a., Das frühkaiserzeitliche Militärlager in der Kaiseraugster Unterstadt. Forschungen in Augst 12 (Augst 1991).

DRINKWATER $1978=$ J. F. Drinkwater, The Rise and Fall of the Gallic Iulii: Aspects of the Development of the Aristocracy of the Three Gauls under the Early Empire. Latomus 37, 1978, 817-850.

DRINKWATER 1983 = J. F. Drinkwater, Roman Gaul. The Three Provinces, 58 BC-AD 260 (Sydney 1983).

DYSON 1975 = St. L. Dyson, Native Revolt Patterns in the Roman Empire, in: ANRW II/3 (Berlin/New York 1975) 138-175.

ECK 2004 = W. Eck, Köln in römischer Zeit. Geschichte einer Stadt im Rahmen des Imperium Romanum (Köln 2004).

ERdKAMP (Hg.) 2002 = P. Erdkamp, (Hg.), The Roman Army and the Economy (Amsterdam 2002). 
FELLMANN $1992=$ R. Fellmann, La Suisse gallo-romaine. Cinq siècles d'histoire (Lausanne 1992).

FERDIÈre 2005 = A. Ferdière, Les Gaules, II ${ }^{\mathrm{e}}$ s. av. J.-C. - V ${ }^{\mathrm{e}}$ s. ap. J.-C. (Paris 2005).

FICHTL $2000=$ S. Fichtl, Le Rhin supérieur et moyen du II ${ }^{\mathrm{e}}$ s. av. J.-C. à la fin du $\mathrm{I}^{\mathrm{er}} \mathrm{s}$. av. J.-C. Quelques réflexions historiques sur les questions du peuplement. Germaina 78, 2000, 21-38.

FISHWICK 1996 = D. Fishwick, The Dedication of the Ara Trium Galliarum. Latomus $55,1996,67-100$.

FLOTTÉ $2016=$ P. Flotté, Un quartier antique de Brocomagus/Brumath (7-9 rue du Général Rampont), Bas-Rhin. Rev. Arch. de l'Est 65, 2016, 27-59.

FlotTÉ U.A. 2006 = P. Flotté u.a., Les agglomérations antiques d'Alsace, in: Bilan scientifique, hors série 2/2 (DRAC Alsace 2006) 31-41.

FORT 2003 = B. Fort, Les militaria et l'occupation militaire de l'agglomération secondaire de Kembs-Cambete (Haut-Rhin) sous le Haut Empire. Rev. Arch. de l'Est 52, 2003 373-402.

Freeman U.A. (Hg.) $2002=$ Ph. Freeman u.a. (Hg.), Proc. XVIII ${ }^{\text {th }}$ Int. Congr. Roman Frontier Stud., Amman Jord., sept. 2000. BAR Intern. Ser. 1084,1 (Oxford 2002).

FURGER-GUNTI 1981 = A. Furger-Gunti, Frühe Auxilien am Rhein. Keltische Münzen in römischen Militärstationen. Arch. Korrbl. 11, 1981, 231-246.

GARCÍA-BELLIDO $2007=$ M. ${ }^{\text {a }}$ P. García-Bellido, Numismatic Documentation on the Arrival of Spanish Troops in Gallia and Germania during the Augustan and Tiberian Period, in: Lehmann/Wiegels (Hg.) 2007, 161-181.

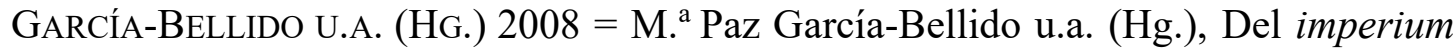
de Pompeyo a la auctoritas de Augusto. Homenaje a Michael Grant. Anejos de AEspA 47 (Madrid 2008).

GECHTER 1979 = M. Gechter, Die Anfänge des Niedergermanischen Limes. BJ 179, 1979, 1-129.

GeCHTER $2003=$ M. Gechter, Die Militärgeschichte am Niederrhein von Caesar bis Tiberius - eine Skizze, in: Th. Grünewald/S. Seiber (Hg.), Kontinuität und Diskontinuität. Germania Inferior am Beginn und am Ende der römischen Herrschaft. Beitr. dt.-niederl. Koll., Kath. Univ. Nijmegen (27.-30.06.2001). RGA Ergbd. 35 (Berlin/New York 2003) 145-161.

GELzER 1919 = M. Gelzer, RE 10, 1919, 478-536 Nr. 154 s. v. Iulius (Tiberius).

GONZENBACH 1963 = V. von Gonzenbach, Die Verbreitung der gestempelten Ziegel der im 1. Jahrhundert in Vindonissa liegenden römischen Truppen. BJ 163, 1963, 76-150.

GoudinEAU $1990=$ C. Goudineau, Les provinces de Gaule: Problèmes d'histoire et géographie, in: Mélanges Pierre Lévêque V: Anthropologie et sociéte. Ann. Litt. Univ. Besançon 429 (Paris 1990) 161-170.

GOUDINEAU 1996 = Chr. Goudineau, Gaul, in: CAH X: The Augustan Empire 43 BC49 AD (Cambridge 1996) 464-502,

GRENIER 1936 = A. Grenier, Tibère et la Gaule. REL 14, 1936, 373-388. 
GRÜNEWALD 1990 = M. Grünewald, Worms, in: Cüppers (Hg.) 1990, 673-679.

GRÜNEWALD 2012 = M. Grünewald, in: Dies./A. Wieczorek (Hg.), Unter dem Pflaster von Worms. Archäologie in der Stadt (Lindenberg 2012) 32-41.

GRÜNEWALD (Hg.) 2001 = Th. Grünewald (Hg.), Germania Inferior. Besiedlung, Gesellschaft und Wirtschaft an der Grenzue der römisch-germanischen Welt. RGA Ergbde. 28 (Berlin/New York 2001).

HAALEBos 2002 = J. K. Haalebos, Die früheste Belegung des Hunerberges in Nijmegen, in: Ph. Freeman u.a. (Hg.), Proc. XVIII ${ }^{\text {th }}$ Int. Congr. Roman Frontier Stud., Amman Jord., sept. 2000. BAR Intern. Ser. 1084,1 (Oxford 2002) 403-414.

HAGENDORN U.A. 2003 = A. Hagendorn u.a., Zur Frühzeit von Vindonissa. Auswertung der Holzbauten der Grabung Windisch-Breite1996-19998. Veröffentl. Ges. Pro Vindonissa 18 (Brugg 2003).

HANEL 2002 = N. Hanel, Zur Datierung der frühkaiserzeitlichen Militärlager von Novaesium (Neuss), in: Freeman u.a. (Hg.) 2002, 497-500.

HANEL 2015 = N. Hanel, Zwischen Agrippa und Drusus - Roms Intervention am Niederrhein in den Jahren 19 und 12 v. Chr. Historische Quellen und archäologische Zeugnisse, in: Lehmann/Wiegels (Hg.) 2015, 165-176.

HÄNGGI 1986 = R. Hänggi, Zurzach AG - Tenedo: Römische Kastelle und Vicus. Arch. Suisse 9, 1986, 149-159.

HARTMANN/SpeIDEL 1991 = M. Hartmann/M. A. Speidel, Die Hilfstruppen des Windischer Heeresverbandes. Zur Besetzungsgeschichte von Vindonissa im 1. Jahrhundert n. Chr. Jahresber. Ges. Pro Vindonissa 1991, 3-33.

HATt 1970 = J. J. Hatt, Histoire de la Gaule romain (120 avant J. C. - 451 après J. C. (Paris $\left.{ }^{3} 1970\right)$.

HATT 1978 = J.-J. Hatt, L'Alsace celtique et romaine, 2200 av. J.-C.à 450 ap. J.-C. (Wettolsheim 1978).

HEINEN $1988=$ H. Heinen, 2000 Jahre Trier. Bd. I: Trier und das Trevererland in römischer Zeit (Trier ${ }^{2} 1988$ ).

HEINRICHS $2001=\mathrm{J}$. Heinrichs, Römische Perfidie und germanischer Edelmut? Zur Umsiedlung protocugernischer Gruppen in den Raum Xanten, in: Grünewald (Hg.) 2001, 54-92.

Herz 1992 = P. Herz, Der Aufstand des Iulius Sacrovir (21 n. Chr.). Gedanken zur römischen Politik in Gallien und ihren Lasten. Laverna 3, 1992, 42-93.

HeRz $2007=$ P. Herz, Finances and Costs of the Roman Army, in: P. Erdkamp (Hg.), A Companion to the Roman Army (Oxford 2007) 306-322.

HoLDER $1980=$ P. A. Holder, Studies in the Auxilia of the Roman Army from Augustus to Trajan. BAR Int. Ser. 79 (Oxford 1980).

JAKOBSMEIER $2018=$ H. Jakobsmeier, Die Gallier-Rede des Claudius aus dem Jahr 48 n. Chr. Historisch-philologische Untersuchungen und Kommentar zur tabula Claudiana aus Lyon. Quellen u. Forsch. zur Ant. Welt 63 (München 2018). 
Jullian $1920=$ C. Julian, Histoire de la Gaule, Bd. IV: Le gouvernement de Rome (Ndr. Paris 1920).

KEMMERs $2007=$ F. Kemmers, A Military Presence of the Lower Rhine before Drusus' Campaignes. The Coin Finds of the Augustan Legionary Fortress at Nijmegen, in: Lehmann/Wiegels (Hg.) 2007, 183-199.

Kemmers $2008=$ F. Kemmers, Marcus Agrippa and the Earliest Roman Fortress at Nijmegen. The Coin Finds from the Hunerberg, in: M. ${ }^{a}$ P. García Bellido u.a. (Hg.), Del Imperium de Pompeyo a la Auctoritas de Augusto. Homenaje M. Grant. Anejos Arch. Esp. Arqu. 47 (Madrid 2008) 165-172.

KORNEMANN $1960=$ E. Kornemann, Tiberius (Stuttgart $1960=$ mehrf. repr.).

KRAFT $1951=$ K. Kraft, Zur Rekrutierung der Alen und Kohorten an Rhein und Donau. Diss. Bernenses I/3 (Bern 1951).

KRIER $1981=$ J. Krier, Die Treverer außerhalb ihrer Civitas. Mobilität und Aufstieg. Trierer Zeitschr. Beih. 5 (Trier 1981).

LE BOHEC (HG.) 1993 = Y. Le Bohec (Hg.), Militaires romains en Gaule civile (Lyon 1993).

LE BOHEC 2019 = Y. Le Bohec, Tacfarinas contre Rome. Étude d'histoire militaire, in: R. Lafer/H. Dolenz/ M.Luik (Hg.), Antiquitates variae. Festschr. K. Strobel zum 65. Geburtstag. Intern. Arch., Stud. Honoraria 39 (Raden 2019) 189-197.

LEHMANN $2018=$ G. A. Lehmann, Imperium und Barbaricum - Neue Befunde und Erkenntnisse zu den römisch-germanischen Auseinandersetzungen im nordwestdeutschen Raum - von der augusteischen Okkupationsphase bis zum GermanienZug des Maximinus Thrax. Österr. Akad. der Wiss., Phil.-Hist. Kl., Sitzungsber. 821 (Wien ${ }^{2} 2018$ ).

LehManN/Wiegels (Hg.) 2007 = G. A. Lehmann/R. Wiegels (Hg.), Römische Präsenz und Herrschaft in Germanien der augusteischen Zeit. Der Fundplatz von Kalkriese im Kontext neuerer Forschungen und Ausgrabungsbefunde. Abhdl. Akad. Wiss. Göttingen, Phil.-hist K1., 3. F., 279 (Göttingen 2007).

LehMANN/Wiegels (Hg.) $2015=$ G. A. Lehmann/R. Wiegels (Hg.), „Über die Alpen und über den Rhein ...". Beiträge zu den Anfängen und zum Verlauf der römischen Expansion nach Mitteleuropa. Abhdlg. Akad. Wiss. Göttingen, N. F. 37 (Berlin/Boston 2015).

LEVICK 1999 = B. Levick, Tiberius the Politician (London/New York $\left.{ }^{2} 1999\right)$.

LEWUILLON $1975=$ S. Lewuillon, Histoire, société et lutte des classes en Gaule. Une féodalité à la fin de la république et au début de l'empire, in: ANRW II/4 (Berlin/New York 1975) 425-583.

LÖHR/TRUNK $2008=$ H. Löhr/M.Trunk, Ein neues Militärlager auf dem Petrisberg bei Trier, in: $\mathrm{M}^{\mathrm{a}} \mathrm{P}$. García-Bellido u.a. (Hg.) 2008, 141-150.

MARSH 1931 = F. B. Marsh, The Reign of Tiberius (Oxford $1931=$ Ndr. 1959).

MARTIN-KILCHER 2015 = St. Martin-Kilcher, Archäologische Spuren der römischen Okkupation zwischen Alpen und Hochrhein und die städtische Besiedlung der civitas Helvetiorum im 1. Jh. v. Chr., in: Lehmann/Wiegels (Hg.) 2015, 235-281. 
MAYER-REPPERT 2003 = P. Mayer-Reppert, Römische Funde aus Konstanz. Vom Siedlungsbeginn bis zur Mitte des 3. Jahrhunderts n. Chr. Fundber. Baden-Württemberg 27, 2003, 441-554.

MeTZLER $1995=$ J. Metzler, Das Treverische Oppidum auf dem Titelberg. Zur Kontinuität zwischen der spätkeltischen und frührömischen Zeit in Nord-Gallien (Luxemburg 1995).

MEYeR 1962 = E. Meyer, Rez.: Kornemann 1960. HZ 194, 1962, 101-103,

Mócsy 1967 = A. Mócsy, Zu den prata legionis, in: Studien zu den Militärgrenzen Roms (Köln/Graz 1967) 211-214.

MóCSY/BARKóCSY 1954 = A. Mócsy/L. Barkóczi. Das Territorium legionis und die canabae in Pannonien (Budapest 1954).

Nesselhauf $1960=$ H. Nesselhauf, Umriss einer Geschichte des obergermanischen Heeres. Jahrb. RGZM 7, 1960, 151-179.

NÜSSLEIN U.A. 2017 = A. Nüsslein u.a., L'Alsace, in: Reddé (Hg.) 2017, 657-682.

OrTH 1970 = W. Orth, Die Provinzialpolitik des Tiberius (Diss. München 1970).

PAunier (Hg.) 2006 = D. Paunier (Hg.), La romanisation et la question de l'héritage celtique. Actes de la table ronde de Lausanne, 17-18 juin 2005. Coll. Bibracte 12/5 (Gloux-en-Glenne 2006).

Poux (Hg.) $2008=$ M. Poux (Hg.), Sur les traces de César. Militaria tardo-républicains en contexte gaulois. Coll. Bibracte 14 (Gloux-en-Glenne 2008).

RAEPSAET-CHARLIER 1998 = M.-Th. Raepsaet-Charlier, Les Gaules et les Germanies, in: C. Lepelley (Hg.), Rome et l'intégration de l'Empire (44 av. J.-C. - 260 ap. J.-C.). II: Approches regionals du Haut-Empire romain (Paris 1998) 143-195.

RASBACH/BECKER $2003=$ G. Rasbach/A. Becker, Die spätaugusteische Stadtgründung in Lahnau- Waldgirmes. Archäologische, architektonische und naturwissenschaftliche Untersuchungen. Germania 81, 2003, 147-199.

REDDÉ 1987 = M. Reddé, Les ouvrages militaires romains en Gaule sous le Haut Empire. Vers un bilan des recherches récentes. Jahrb. RGZM 34, 1987, 343-368.

REDDÉ 1991 = M. Reddé, Die militärische Besetzung Galliens unter Augustus. Überlegungen zu den römischen Befestigungen des französischen Territoriums, in: B. Trier (Hg.), Die römische Okkupation nördlich der Alpen zur Zeit des Augustus. Kolloquium Bergkamen 1989. Bodenaltertümer Westfalens 26 (Münster 1991) 41-48.

REDDÉ (Hg.) 1996 = M. Reddé (Hg.), L’armée romaine en Gaule (Paris 1996).

REDDÉ $2005=$ M. Reddé, Ou sont passés les castella Drusiana. Reflexions critiques sur les débuts de l'occupation militaire romain dans le bassin du Rhin supérieur. Revue des Études Militaires Anciennes (REMA) 2, 2005, 69-87.

REDDÉ 2008/1 = M. Reddé, Gallia Comata entre César y Augusto, in: García-Bellido u.a. (Hg.) 2008, 11-27.

REDDÉ 2008/2 = M. Reddé, Postface, in: M. Poux (Hg.) 2008, 433-437. 
REDDÉ 2009 = M. Reddé, Militaires romaines en Gaule civile. Cahiers Glotz 20, 2009, 173-183.

REDDÉ (Hg.) 2009 = M. Reddé (Hg.), Oedenburg (I). Fouilles françaises, allemandes et suisses à Biesheim et Kunheim, Haut-Rhin, France, vol. I: Les campes militaires julio-claudiens. RGZM Monogr. 79,1 (Mainz 2009).

REDDÉ 2011/1 = M. Reddé, „ut eo terrore commeatus Gallia adventantes interciperentur" (Tacite, Hist., V,23). La Gaule intérieure et le ravitaillement de l'armée du Rhin. REA 113, 2011, 489-509.

REDDÉ 2011/2 = M. Reddé, L'armée romaine et les peuples Gaulois de César à Auguste, in: R. Wiegels/G. Moosbauer (Hg.), Fines imperii - imperium sine fine. Beitr. Kongr. Osnabrück, 14-18. Sept. 2009. Osnabrücker Forschungen zu Altertum u. Antike-Rezeption 14 (Rahden/Westf. 2011) 63-73.

REDDÉ 2013 = M. Reddé, Die Siedlung und die Militärlager von Oedenburg aus römischer Zeit, in: Atlas historique d'Alsace, Université de Haute Alsace, 2013. www.atlas.historique.alsace.uha.fr $(01.09 .2020)$

REDDÉ 2015 = M. Reddé, Befunde und Erkenntnisse zu den römischen Militäranlagen am Oberrhein in augusteischer und tiberischer Zeit, in: Lehmann/Wiegels (Hg.) 2015, 299-311.

REDDÉ (HG.) 2017 = M. Reddé (Hg.), Gallia Rustica I: Les campagnes du nord-est de la Gaule de la fin de l'âge du fer à l'antiquité tardive. Mémoires 49 (AUSONIUS/Bordeaux 2017).

REMESAL RoDRÍGUEZ 1997 = J. Remesal Rodríguez, Heeresversorgung und die wirtschaftlichen Beziehungen zwischen der Baetica und Germanien (Stuttgart 1997).

RIESS 2003 = W. Riess, Die Rede des Claudius über das ius honorum der gallischen Notablen: Forschungsstand und Perspektiven. REA 105, 2003, 211-249.

RITTERLING $1906=$ E. Ritterling, Zur Geschichte des römischen Heeres in Gallien unter Augustus. BJ 114-115, 1906, 159-188.

RITTERLING 1924/25 = E. Ritterling, RE 12, 1924/25, 1211-1829 s.v. Legio.

ROYMANS 2004 = N. Roymans, Ethnic Identity and Imperial Power. The Batavians in the Early Roman Empire (Amsterdam 2004).

RÜGER $1968=$ Ch. B. Rüger, Germania inferior (Köln/Graz 1968).

SANDER 1958 = E. Sander, Das Recht des römischen Soldaten. Rhein. Mus. Philol. 101, $1958,152-234$.

Schnitzler/Kuhnle (Hg.) 2010 = B. Schnitzler/G. Kuhnle (Hg.), Strasbourg-Argentorate. Un camp légionnaire sur le Rhin ( $\mathrm{I}^{\mathrm{er}}$ au $\mathrm{IV}^{\mathrm{e}}$ siècle après J.-C.) (Strasbourg 2010).

SCHNURBEIN 2003 = S. von Schnurbein, Augustus in Germania and his New 'Town' at Waldgirmes East of the Rhine. Journ. Rom. Arch. 16, 2003, 93-107.

SCHÖNBERGER $1985=$ H. Schönberger, Die römischen Truppenlager der frühen und mittleren Kaiserzeit zwischen Nordsee und Inn. Ber. RGK 66, 1985, 321-407. 
SCHREMPP U.A. 2015 = J. Schrempp/M. Machura/J. Lauber/K. Kortüm/A. Heising, Frühe Germanen am Oberrhein? Ein neues Gräberfeld mit Waffenbeigaben in Diersheim. Arch. Ausgr. Baden-Wurttemberg 2015 (2016) 158-161.

SCHREMPP U.A. 2016 = J. Schrempp/A. Heising/J. Lauber/K.Kortüm, Diersheims „Sueben" - Zeugen tiberischer Grenzpolitik am Oberrhein, Arch. Ausgr. BadenWürttemberg 2016 (2017) 176-179.

SCHUlTEN 1894 = A. Schulten, Das Territorium legionis. Hermes 29, 1894, 481-516.

SEAGER $2005=$ R. Seager, Tiberius (Oxford $\left.{ }^{2} 2005\right)$.

SPAUL $1994=$ J. E. H. Spaul, Ala² . The Auxiliary Cavalry Units of the Pre-Diocletianic Imperial Roman Army (Andover 1994).

SPAUl $2000=$ J. Spaul, Cohors ${ }^{2}$. The Evidence for and a Short History of the Auxiliary Infantry Units of the Imperial Roman Empire. BAR Int. Ser. 841 (Oxford 2000).

SPEIDEL 1996 = M. A. Speidel, Die römischen Schreibtafeln von Vindonissa. Veröffentl. Ges. Pro Vindonissa 12 (Brugg 1996).

STEIN (/RITTERLING) $1932=$ E. Stein, Die Kaiserlichen Beamten und Truppenkörper im römischen Deutschland unter dem Prinzipat (mit Benützung von E. Ritterlings Nachlass). Beitr. Verwaltungs- und Heeresgesch. von Gallien und Germanien 1 (Wien 1932).

SYME 1958 = R. Syme, Tacitus, 2 Bde. (Oxford 1958).

TARPIN $2006=$ M. Tarpin, Territoires celtiques, civitates gallo-romaies: quelle continuité?, in: Paunier (Hg.) 2006, 29-50.

THEVENOT 1960/61=E. Thevenot, Sacrovir, ultime champion de la liberté chez les Eduens. Mém. Soc. Éduenne, N. S. 50, 1960/61, 241-255 u. 273-299.

TIMPE $1975=$ D. Timpe, Zur Geschichte der Rheingrenze zwischen Caesar und Drusus, in: E. Lefèvre (Hg.), Monumentum Chiloniense. Studien zur augusteischen Zeit. Festschr. E. Burck zum 70. Geburtstag 1975 (Amsterdam) 124-147 = Ndr. in: D. Timpe, Römisch-germanische Begegnung in der späten Republik und frühen Kaiserzeit. Voraussetzungen - Konfrontationen - Wirkungen. Gesammelte Studien. Beitr. zur Altkde. 233 (München/Leipzig 2006) 147-170.

TIMPE 1998 = D. Timpe, Germanen - historisch, in: Die Germanen (Studienausgabe). $\mathrm{RGA}^{2}$ (Berlin/New York 1998) 1-65.

TIMPE 2006 = D. Timpe, Römisch-germanische Begegnung in der späten Republik und frühen Kaiserzeit. Voraussetzungen - Konfrontationen - Wirkungen. Gesammelte Studien. Beitr. zur Altkde. 233 (München/Leipzig 2006).

URBAN $1999=$ R. Urban, Gallia rebellis. Erhebungen in Gallien im Spiegel antiker Zeugnisse. Historia ES 129 (Stuttgart 1999).

VANDERHOEVEn 2013 = A. Vanderhoeven, Die römische Stadt Tongeren, in: R. von Haehling/A. Schaub (Hg.), Römisches Aachen. Archäologisch-historische Aspekte zu Aachen und der Euregio (Regensburg 2013) 387-411. 
VITTINGHOFF 1974 = Fr. Vittinghoff, Das Problem des „Militärterritoriums“ in der vorseverischen Zeit, in: Diritti locali nelle provincie romane con particolare riguardo alle condizioni giuridiche del suolo. Atti del convegno internazionale (Roma, 2628 ottobre 1971). Acad. Naz. dei Lincei (Roma 1974) 109-124.

Wells $1972=$ C. M. Wells, The German Policy of Augustus. An Examination of the Archaeological Evidence (Oxford 1972).

WeNDLING $2005=\mathrm{H}$. Wendling, Sasbach am Kaiserstuhl - Siedlungen auf und im Umfeld des Limberges, Kreis Emmendingen, in: Kelten am Oberrhein (Esslingen 2005) 97-99.

WHITTAKeR $1994=$ C. R. Whittaker, Frontiers of the Roman Empire. A Social and Economic Study (Baltimore/London 1994).

WIEGELS $1989=$ R. Wiegels, Solum Caesaris - Zu einer Weihung im römischen Walheim. Chiron 19, 1989, 61-102. = Ndr. in: Wiegels 2010, 195-234.

WIEGELS $2007=$ R. Wiegels, Ein Reitergrabstein aus dem oberelsässischen Kembs (Haut-Rhin), in: U. Fellmeth/P. Guyot/H. Sonnabend (Hg.), Historische Geographie der Alten Welt: Grundlagen, Erträge, Perspektiven. Festgabe für Eckart Olshausen aus Anlass seiner Emeritierung (Hildesheim/Zürich/New York 2007) 381397. $=$ Ndr. in: Wiegels 2010, 567-580.

WIEGELS $2010=$ R. Wiegels, Kleine Schriften zur Epigraphik und Militärgeschichte der germanischen Provinzen, hg. von K. Matijević/W. Spickermann (Stuttgart 2010).

WIERSCHOWSKI $1984=$ L. Wierschowski, Heer und Wirtschaft. Das römische Heer der Prinzipatszeit als Wirtschaftsfaktor (Bonn 1984).

Wightman $1970=$ E. M. Wightman, Roman Trier and the Treveri (London 1970).

WightMAn 1974 = E. M. Wightman, La Gaule chevelue entre César et Auguste, in: Actes du IX ${ }^{\mathrm{e}}$ Congrès Int. d'Études sur les Frontiers Romaines, Mamaia , 6-13 septembre 1972 (Bukarest 1974) 473-483.

Wightman 1977 = E. M. Wightman, Soldier and Civilian in Early Roman Gaul, in: Akten des XI. Int. Limeskongresses 1976 (Budapest 1977) 75-86.

WolfF 1977 = H. Wolff, Civitas und Colonia Treverorum. Historia 26, 1977, 204-242.

WOLTERS $1990=$ R. Wolters, Römische Eroberung und Herrschaftsorganisation in Gallien und Germanien. Zur Entstehung und Bedeutung der sogenannten KlientelRandstaaten. Bochumer hist. Stud., Alte Geschichte 8 (Bochum 1990).

WOLTERS $1998=$ R. Wolters, Keltische Münzen in römischen Militärstationen und die Besoldung römischer Hilfstruppen in spätrepublikanischer und Frühaugusteischer Zeit. Tyche 3-4, 1998, 261-272.

WOLTERS $2001=$ R. Wolters, Germanische Mobilität und römische Ansiedlungspolitik: Voraussetzungen und Strukturen germanischer Siedlungsbewegungen im römischen Grenzland, in: Grünewald (Hg.) 2001, 146-168.

Woolf 1998 = G. Woolf, Becoming Roman. The Origins of Provincial Civilization in Gaul (Cambridge $1998=$ u.a. Ndr. 2009). 
Frankfurter elektronische Rundschau zur Altertumskunde 42 (2020)

YAVETZ 1999 = Z. Yavetz, Tiberius. Der traurige Kaiser (München $1999=$ mehrf. repr.).

ZEHNER 2010 = M. Zehner, La céramique de la Tène finale et du début de l'époque romaine en Alsace (Strasbourg 2010).

\section{Kontakt zum Autor:}

Prof. Dr. Rainer Wiegels

Birkenstr. 9a

79256 Buchenbach

E-Mail: rainer.wiegels@uni-osnabrueck.de

\section{(cc) EY}

Dieser Beitrag ist lizenziert unter einer Creative Commons Namensnennung - 4.0 International Lizenz. 